Acta Crystallographica Section B

Structural

Science

ISSN 0108-7681

\section{Angel Vegas, ${ }^{\text {a* }}$ Raymond L. Martin $^{b}$ and D. J. M. Bevan ${ }^{c}$}

aInstituto de Química Física 'Rocasolano', CSIC C/Serrano 119, 28006 Madrid, Spain, 'bonash University, School of Chemistry, Clayton, Victoria, Australia, and ${ }^{\mathbf{c}}$ The Flinders University of South Australia, School of Chemistry, Physics and Earth Sciences, Bedford Park, South Australia

Correspondence e-mail: avegas@iqfr.csic.es

\title{
Compounds with a 'stuffed' anti-bixbyite-type structure, analysed in terms of the Zintl-Klemm and coordination-defect concepts
}

The bixbyite structure $\left(\mathrm{Mn}_{2} \mathrm{O}_{3}\right)(I a \overline{3})$ is often described as a distorted face-centered cubic (f.c.c.) array of $\mathrm{Mn}$ atoms, with $\mathrm{O}$ atoms occupying $3 / 4$ of the tetrahedral holes. The empty $M_{4}$ tetrahedra are centred at $16 c$. In anti-bixbyite structures $\left(\mathrm{Mg}_{3} \mathrm{~N}_{2}\right)$, cation vacancies are centred in empty $\mathrm{N}_{4}$ tetrahedra. If 16 hypothetical atoms were located at this site they would form the structure of $\gamma$-Si. This means that anti-bixbyite structures are ideally prepared to accommodate $\mathrm{Si}(\mathrm{Ge})$ atoms at these holes. Several compounds $\left(\mathrm{Li}_{3} \mathrm{AlN}_{2}\right.$ and $\left.\mathrm{Li}_{3} \mathrm{ScN}_{2}\right)$ fully satisfy this expectation. They are really anti-bixbyites 'stuffed' with $\mathrm{Al}(\mathrm{Sc})$. The presence of these atoms in $16 c$ is illuminated in the light of the extended Zintl-Klemm concept (EZKC) [Vegas \& García-Baonza (2007). Acta Cryst. B63, 339-345], from which a compound would be the result of 'multiple resonance' pseudo-structures, emerging from electron transfers between any species pair (like or unlike atoms, cations or anions). The coordination-defect (CD) concept [Bevan \& Martin (2008). J. Solid State Chem. 181, 2250-2259] is also consistent with the EZKC description of the pseudostructures. A more profound insight into crystal structures is gained if one is not restricted to the contemplation of classical anions and cations in their conventional oxidation states.

\section{Introduction}

The mineral bixbyite $\left(\mathrm{Mn}_{2} \mathrm{O}_{3}\right)$ and isostructural compounds like $\mathrm{Sc}_{2} \mathrm{O}_{3}$ and $\mathrm{In}_{2} \mathrm{O}_{3}$ (Zachariasen, 1928) are cubic. The space group of bixbyite is $I a \overline{3}$, with $Z=16$. The Mn atoms occupy two crystallographically independent sites, $8 b$ and $24 d$, whereas all the $\mathrm{O}$ atoms are equivalent, located at $48 e$. The structure has often been described (Wells, 1975) as a slightly distorted f.c.c. array of $\mathrm{Mn}$ atoms, with the $\mathrm{O}$ atoms occupying $\frac{3}{4}$ of the tetrahedral holes. Hence, bixbyite has also been regarded as an anion-deficient, fluorite-related structure, $\mathrm{M}_{4} \mathrm{O}_{6} \square_{2}$, with the vacant site, designated $\square$, located in the anion sublattice.

There are well known anti-bixbyite-type compounds such as $\mathrm{N}_{2} \mathrm{Mg}_{3}$ (von Stackelberg \& Paulus, 1933): this example can be similarly regarded as a cation-deficient, anti-fluorite structure, $\mathrm{N}_{2} \mathrm{Mg}_{3} \square_{M}$, with the vacant site, $\square_{M}$, now located in the cation sublattice.

The similarity (topology and bond lengths) of cation arrays with the structures of the parent metals was also reported by Ramos-Gallardo \& Vegas (1995), as an example of what have been called 'real stuffed alloys' (Martínez-Cruz et al., 1994; Vegas, 2000; Vegas \& Jansen, 2002; Vegas et al., 2001). Very recently, Bevan \& Martin (2008) have reported a crystalchemical study in which their 'coordination-defect theory' of anion vacancies or voids was applied to analyse the structures of the anion-deficient, fluorite-related sesquioxide minerals bixbyite, braunite and parwelite.
Received 4 August 2008 Accepted 20 October 2008 
In that paper, Bevan \& Martin (2008) made an unusual observation, i.e. they noticed that in bixbyite the 16 vacancies (a quarter of the tetrahedral holes in the f.c.c. cation array) correspond to the positions of the $16 c$ site of the space group $I a \overline{3}$, and that when an anion vacancy, $\square$, is located at this site, the pattern represented in Fig. 1(b) is obtained. Looking at this array, we soon recognized that the pattern is coincident with that of the quenched high-pressure $\gamma$ phases of Si and Ge (Wentorf \& Kasper, 1963; Kasper \& Richards, 1964; see Fig. $1 a)$ : these have not only the same space group $(I a \overline{3})$ as bixbyite, but the $\mathrm{Si}(\mathrm{Ge})$ atoms occupy the same $16 c$ sites as the bixbyite vacancies. Both structures are compared in Figs. 1(a) and $(b)$.

At first glance, this feature could be considered as an accidental and unremarkable coincidence. However, encouraged by our intuition, and taking into account that many structures can be illuminated by the Zintl-Klemm concept (hereafter ZKC; Zintl, 1939; Klemm, 1958), we decided that this structural coincidence was worthy of a deeper analysis. This decision was based on two observed features. On the one hand, there was our previous experience of how the elemental structures were often preserved in the compounds (Vegas, 2000; Vegas \& Jansen, 2002), and on the other because the presence of 'foreign' atoms can stabilize a given structure, as happens in the Zintl phases (Santamaría-Pérez \& Vegas, 2003;

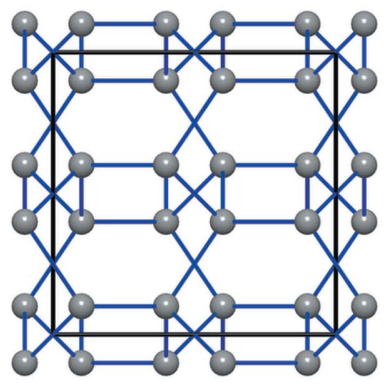

(a)

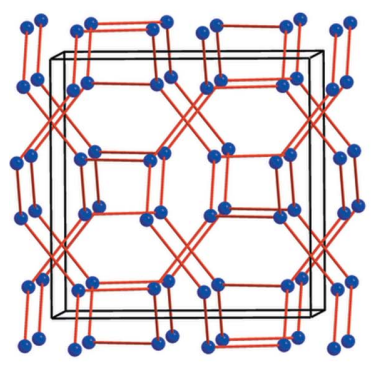

(d)

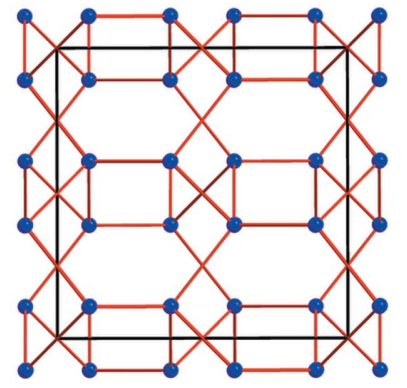

(b)

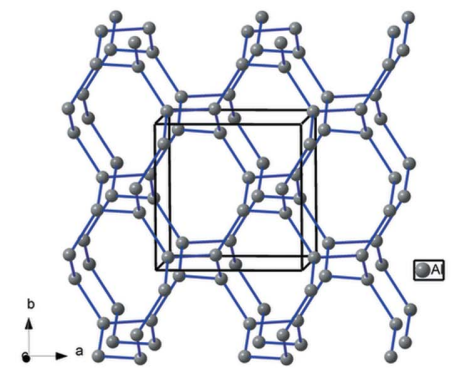

$(e)$

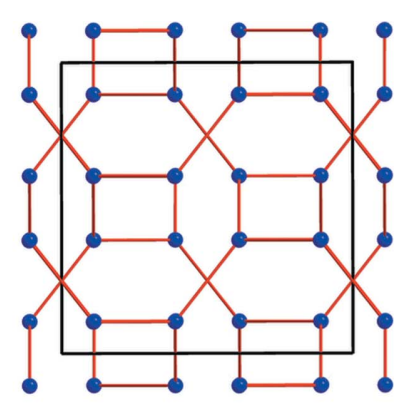

(c)

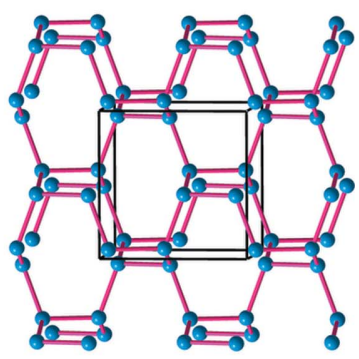

$(f)$
Figure 1

(a) A projection of the cubic structure of the metastable HP phase $\gamma$-Si $(\mathrm{Ge})$. (b) The substructure of the fictitious $\mathrm{V}$ atoms (voids), occupying the $16 c$ site in the bixbyite structure $\mathrm{Mn}_{2} \mathrm{O}_{3}$. (c) The same drawing as (b) in which some contacts (bonds) have been eliminated to show clearly how the structure can be decomposed into two three-connected subsets. (d) Perspective view of $(c)$ to emphasize the threefold connection in each subset, which is characteristic of the Group 15 elements $(\mathrm{N}, \mathrm{P})$. Note the existence of both tetragonal and octagonal helices, perpendicular to the projection plane. (e) The $\mathrm{Al}$ sub-array in $\mathrm{Sr}_{3} \mathrm{Al}_{2} \mathrm{O}_{5} \mathrm{Cl}_{2}$, where the $\mathrm{Al}$ atoms are converted into $(\Psi-\mathrm{P})$, forming a $\left(\Psi-\mathrm{P}_{2} \mathrm{O}_{5}\right)$ skeleton. The network is identical to the subsets forming both the HP-Si $(\mathrm{Ge})$ and the $\mathrm{V}$ voids in bixbyite. $(f)$ The structure of the high-pressure, high-temperature $\mathrm{N}$ to show its similarity with both the $\mathrm{Al}$ subarray represented in $(e)$ and the two subsets of HP-Si, represented in $(d)$.
Santamaría-Pérez et al., 2005; Vegas \& García-Baonza, 2007). This feature occurs not only in alloys but also in oxides and extension of the Zintl-Klemm , the ideal sites to accommodate an atom such as Si or Ge: in Si(Ge) atoms that, when pent, should necessarily be located in these holes'. study to ascertain whether 'stuffed' anti-bixbyite-type compounds of the general stoichiometry $M_{3} \mathrm{Si} X_{2}$, could exist, and also whether the $\mathrm{Si}$ (or indeed other) atoms would be at the predicted positions. contains the following quote: 'Focussing on the $\left[\mathrm{Sc}\left(\mathrm{N}^{3-}\right)_{4 / 2}\right]$ As the and $\alpha-\mathrm{Ca}_{3} \mathrm{~N}_{2}$ (anti-bixbyite), the $\left[\mathrm{Sc}\left(\mathrm{N}^{3-}\right)\right.$ framework consequently corresponds to the occupation of the unoccupied tetrahedral holes in the anti-bixbyite structure with Sc'. However, Sc is not $\mathrm{Si}(\mathrm{Ge})$ ! The electron configuration and stereochemical preferences of Sc usually differ substantially from those of Si and Ge.

\section{Results and discussion}

\subsection{Extended Zintl-Klemm concept}

If our hypothesis is valid, the existence of some compounds of the general formula $M_{3} \mathrm{Si} X_{2}$ would be expected. For such a compound, the sub-array $M_{3} X_{2}$ should have the desired antibixbyite structure, and the foreign atom $(\mathrm{Si}, \mathrm{Ge})$ should be located at the $16 c$ site of the space group $I a \overline{3}$. Considered as a whole, without any distinction between cations, the compound would be formulated as $M_{4} X_{2}$, which corresponds to the stoichiometry of an anti-fluorite structure, i.e. $\mathrm{M}_{2} \mathrm{X}\left(\mathrm{Mg}_{2} \mathrm{Si}\right.$, for example; Owen \& Preston, 1924), rather than that of fluorite.

We now know of the existence of numerous ternary compounds with the same space group $I a \overline{3}$, such as, for example, $\mathrm{Li}_{3} \mathrm{AlN}_{2}$, $\mathrm{Li}_{3} \mathrm{GaN}_{2}, \mathrm{Li}_{3}\left[\mathrm{Ge}_{0.67} \mathrm{Li}_{0.33}\right] \mathrm{N}_{2}$ and, 
Table 1

List of stuffed anti-bixbyite-type compounds.

Those crystallizing in the $I a \overline{3}$ space group preserve the space group of bixbyite itself. The stuffing elements occupy the $16 c$ site of $I a \overline{3}$. In $\mathrm{Li}_{6}[\mathrm{Li}, \mathrm{V}] \mathrm{N}_{4}$, crystallizing in the subgroup $P a \overline{3}$, the lower symmetry preserves the unit-cell dimensions but separates both $\mathrm{V}$ and $\mathrm{Li}$ atoms into two distinct $8 c$ sites.

\begin{tabular}{llll}
\hline Compound & $\begin{array}{l}\text { Stuffing } \\
\text { cation }\end{array}$ & $\begin{array}{l}\text { Space } \\
\text { group }\end{array}$ & References \\
\hline $\mathrm{Li}_{3} \mathrm{AlN}_{2}$ & $\mathrm{Al}$ & $I a \overline{3}$ & Juza \& Hund (1948) \\
$\mathrm{Li}_{3} \mathrm{GaN}_{2}$ & $\mathrm{Ga}$ & $I a \overline{3}$ & Juza \& Hund (1948) \\
$\mathrm{Li}_{3} \mathrm{ScN}_{2}$ & $\mathrm{Sc}$ & $I a \overline{3}$ & Niewa et al. $(2003)$ \\
$\mathrm{Li}_{3}\left[\mathrm{Ge}_{0.67} \mathrm{Li}_{0.33}\right] \mathrm{N}_{2}$ & $\mathrm{Ge}, \mathrm{Li}$ & $I a \overline{3}$ & Juza et al. $(1953)$ \\
$\mathrm{Li}_{3}\left[\mathrm{Si}_{0.67} \mathrm{Li}_{0.33}\right] \mathrm{N}_{2}$ & $\mathrm{Si}, \mathrm{Li}$ & $I a \overline{3}$ & Juza et al. $(1953)$ \\
$\mathrm{Li}_{3}\left[\mathrm{Ti}_{0.67} \mathrm{Li}_{0.33}\right] \mathrm{N}_{2}$ & $\mathrm{Ti}, \mathrm{Li}$ & $I a \overline{3}$ & Juza et al. $(1953)$ \\
$\mathrm{Li}_{6}[\mathrm{MnLi}] \mathrm{N}_{4}$ & $\mathrm{Mn}, \mathrm{Li}$ & $P a \overline{3}$ & Niewa et al. $(2001)$ \\
$\mathrm{Li}_{6}[\mathrm{VLi}] \mathrm{N}_{4}$ & $\mathrm{~V}, \mathrm{Li}$ & $P a \overline{3}$ & Niewa \& Kniep (2001) \\
$\mathrm{Li}_{6}[\mathrm{NbLi}] \mathrm{N}_{4}$ & $\mathrm{Nb}, \mathrm{Li}$ & $P a \overline{3}$ & Vennos \& DiSalvo (1992) \\
$\mathrm{Li}_{6}[\mathrm{TaLi}] \mathrm{N}_{4}$ & $\mathrm{Ta}, \mathrm{Li}$ & $P a \overline{3}$ & Wachsmann \& Jakobs $(1992)$ \\
\hline & & &
\end{tabular}

more recently, another such compound, $\mathrm{Li}_{3} \mathrm{ScN}_{2}$, as quoted above. Then there are other compounds of the general formula $\mathrm{Li}_{3}\left[\left(M^{\mathrm{IV}}\right)_{0.67} \mathrm{Li}_{0.33}\right] \mathrm{N}_{2}$, with $M^{\mathrm{IV}}=\mathrm{Si}$, Ti. In all of these, the cations of the $\left[\left(M^{\mathrm{IV}}\right)_{0.67} \mathrm{Li}_{0.33}\right]$ group are disordered.

Furthermore, there is also a group of compounds, $\mathrm{Li}_{7} M^{\mathrm{V}} \mathrm{N}_{4}$ $\left(M^{\mathrm{V}}=\mathrm{Mn}, \mathrm{V}, \mathrm{Nb}, \mathrm{Ta}\right)$, which crystallize in the space group $\mathrm{Pa} \overline{3}$, a sub-group of $I a \overline{3}$ from which the body-centering operation has been lost. The formulae should more correctly be written as $\mathrm{Li}_{6}\left[M^{\mathrm{V}} \mathrm{Li}\right] \mathrm{N}_{4}$, by analogy with $\mathrm{Li}_{3}\left[\left(M^{\mathrm{IV}}\right)_{0.67} \mathrm{Li}_{0.33}\right] \mathrm{N}_{2}\left(M^{\mathrm{IV}}=\right.$ $\mathrm{Ge}$ ), since the $\mathrm{Li}$ and $M^{\mathrm{V}}$ atoms in the square brackets are now ordered on two $8 c$ sites of the space group, corresponding almost exactly with the $16 c$ sites of $I a \overline{3}$. All these compounds, as well as their references are summarized in Table 1.

In these various compounds, it is encouraging to see that the $\mathrm{Al}(\mathrm{Ga}, \mathrm{Sc})$ atoms, the disordered sets $\left[\left(M^{\mathrm{IV}}\right)_{0.67} \mathrm{Li}_{0.33}\right]$ and the ordered sets $\left[\mathrm{Li} M^{\mathrm{V}}\right]$ are all located in the relevant sites which give rise to the $\gamma$-Si framework. However, the crucial question is: why are the diverse atoms of these sets disposed in the tetrahedral network expected for $\mathrm{Si}(\mathrm{Ge})$ ? The first impression might be that our assumption was not justified, and indeed this raises the possibility that any of the other atomic species could be lodged in these voids. However, this apparent contradiction can be resolved in the context of the extended Zintl-Klemm concept (Vegas \& García-Baonza, 2007), as we shall demonstrate below. It is important to note that the application of the Zintl-Klemm concept to a compound invariably allows for several alternative structural interpretations. This concept and, especially, Klemm's pseudo-atom concept, correlate the stereochemical properties of an atom with the transfer of electrons from a donor to an acceptor atom. Both atoms are thereby transposed to pseudo-atoms, each with a new electronic configuration and stereochemical properties (Santamaría-Pérez \& Vegas, 2003; Santamaría-Pérez et al., 2005; Vegas \& García-Baonza, 2007). It is generally accepted that the pseudo-atoms are denoted by the prefix $\Psi$ (See Table 2). For example, when an $\mathrm{Al}$ atom accepts one electron, it becomes isoelectronic with a $\mathrm{Si}$ pseudo-atom, designated as $(\Psi-\mathrm{Si})$. These authors have also provided examples of the general application of the Zintl concept to explain the struc- ture of several inorganic structures, and to demonstrate how many of them are stabilized by the presence of foreign atoms.

In the $\mathrm{Li}_{3} \mathrm{Al}(\mathrm{Ga}, \mathrm{Sc}) \mathrm{N}_{2}$ structure (Juza \& Hund, 1948; Niewa et al., 2003) the $\mathrm{Al}(\mathrm{Ga}, \mathrm{Sc})$ or $\Psi-\mathrm{Si}(\mathrm{Ge})$ atoms are fourconnected, following the $8-N$ rule, as occurs with most structures of the $p$-block elements. The tetrahedral connection (characteristic of the Group 14 elements) is made in such a way that what are seen as octagons and squares in projection are really octagonal and square helices about $22_{1}$ axes perpendicular to the projection plane. See Figs. $1(d),(e)$ and $(f)$. It is immediately evident that these skeletons resemble those of the Si sub-array in the quartz structure in which trigonal and hexagonal helices coexist.

In the structures of the $\gamma$-Si(Ge) phases the four linkages are almost equal ( $\mathrm{Si}-\mathrm{Si}$ distances of $3 \times 2.38 \AA, 1 \times 2.37 \AA$ ), whereas in $\mathrm{Li}_{3} \mathrm{AlN}_{2}$, the equivalent $\mathrm{Al}-\mathrm{Al}$ distances show a somewhat greater difference $(3 \times 3.61 \AA, 1 \times 3.85 \AA)$ : in the case of $\mathrm{Li}_{3} \mathrm{ScN}_{2}$, these distances are $3 \times 3.55$ and $1 \times 4.25$. If the single longer linkage in each case were to be omitted, we would obtain the pattern represented in Fig. 1(c) for $\mathrm{Li}_{3} \mathrm{AlN}_{2}$. This consists of two infinite, interpenetrating subsets. These independent, three-connected $\mathrm{Al}$ networks simply interpenetrate, as shown in Figs. 1(c) and $(d)$.

It should be remarked that this three-connected network is the one expected for the Group 15 elements (N, P, As etc.), and has been identified as the $\mathrm{Al}$ sub-array in $\mathrm{Sr}_{3} \mathrm{Al}_{2} \mathrm{O}_{5} \mathrm{Cl}_{2}$ (Santamaría-Pérez, 2006). This skeleton is represented in Fig. $1(e)$ and its structure can be interpreted in light of the $\mathrm{ZKC}$. Here, the three $\mathrm{Sr}$ atoms act as donors. One of them transfers two electrons to the two $\mathrm{Cl}$ atoms. The two remaining $\mathrm{Sr}$ atoms transfer their four valence electrons to the $\mathrm{Al}$ atoms, converting them into $(\Psi-\mathrm{P})$ and, consequently, the $\mathrm{Al}_{2} \mathrm{O}_{5}$ group becomes $\left(\Psi-\mathrm{P}_{2} \mathrm{O}_{5}\right)$. Compare Figs. $1(d)$ and $(e)$.

The structural behaviour of molecular $\mathrm{N}_{2}$ illustrates this interpretation. At $115 \mathrm{GPa}$ and $2600 \mathrm{~K}$, nitrogen undergoes a phase transition adopting the three-connected structure represented in Fig. 1(f) (Eremets et al., 2004). The structure is also cubic, $I 2{ }_{1} 3$, with $a=3.45 \AA$. The $\mathrm{N}$ atoms are located at $8 a$ ( $x, x, x: x=0.067$ ), forming the same structure as the $\mathrm{Al}$ atoms ( $\Psi$-P) in $\mathrm{Sr}_{3} \mathrm{Al}_{2} \mathrm{O}_{5} \mathrm{Cl}_{2}$ (Leib \& Müller-Buschbaum, 1986). The important issue here is that the $\mathrm{Al}$ network, discovered in $\mathrm{Sr}_{3} \mathrm{Al}_{2} \mathrm{O}_{5} \mathrm{Cl}_{2}$ (Santamaría-Pérez \& Vegas, 2003), is by no means a hypothetical structure for the Group 15 elements but it really exists as a stable phase for nitrogen! Compare Figs. $1(e)$ and $1(f)$. The similarity of this network with the $\mathrm{Si}$ skeleton ( $\Psi$-P) in the Zintl phase $\mathrm{SrSi}_{2}$ (Pringle, 1972), is also remarkable.

The structure is also related to the four-connected networks of $\beta$ - BeO (Smith et al., 1965), $\mathrm{CrB}_{4}$ (Andersson \& Lundström, 1968), anorthite $\left(\mathrm{CaAl}_{2} \mathrm{Si}_{2} \mathrm{O}_{8}\right.$; Takeuchi et al., 1973) and the AlP sub-arrays of two polymorphs of $\mathrm{AlPO}_{4} \cdot 2 \mathrm{H}_{2} \mathrm{O}$ (the minerals variscite and metavariscite; Kniep \& Mootz, 1973; Kniep et al., 1977; Kniep, 1978). In all these structures, represented in Fig. 2, the involved atoms form puckered layers of octagons and squares (the $\mathbf{4 . 8 ^ { 2 }}$ nets), instead of the helices existing in the $\gamma$ - $\mathrm{Si}(\mathrm{Ge})$ structure. Compare the structures drawn in Figs. 1 and 2. 
Table 2

Possible electron redistributions for species relevant to the present work.

The Zintl-Klemm notation describes the electron redistribution, so that, in the overall electron count for the elements concerned, the superscript -1 (rather than 1-), for example, represents an excess electron on that atom; the superscript +1 represents a one-electron loss. Thus, $\mathrm{Li}^{+1}$ is $(\Psi-\mathrm{He}), \mathrm{Al}^{-1}$ and $\mathrm{N}^{-1}$ are $(\Psi-\mathrm{Si})$ and $(\Psi-$ $\mathrm{O})$, respectively, and $\mathrm{Al}^{+3}$ is $(\Psi-\mathrm{Ne})$.

\begin{tabular}{lllllll}
\hline \multicolumn{2}{l}{ Electron donation } & & \multicolumn{3}{l}{ Electron acceptance } \\
\cline { 1 - 2 } \cline { 5 - 6 } & 2 & 1 & Atom & 1 & 2 & 3 \\
\hline $\mathrm{N}^{+3}=(\Psi-\mathrm{Be})$ & $\mathrm{N}^{+2}=(\Psi-\mathrm{B})$ & $\mathrm{N}^{+1}=(\Psi-\mathrm{C})$ & $\mathrm{N}^{0}$ & $\mathrm{~N}^{-1}=(\Psi-\mathrm{O})$ & $\mathrm{N}^{-2}=(\Psi-\mathrm{F})$ & $\mathrm{N}^{-3}=(\Psi-\mathrm{Ne})$ \\
& $\mathrm{Li}^{+2}=(\Psi-\mathrm{H})$ & $\mathrm{Li}^{+1}=(\Psi-\mathrm{He})$ & $\mathrm{Li}^{0}$ & $\mathrm{Li}^{-1}=(\Psi-\mathrm{Be})$ & $\mathrm{Li}^{-2}=(\Psi-\mathrm{B})$ & $\mathrm{Li}^{-3}=(\Psi-\mathrm{C})$ \\
$\mathrm{Al}^{+3}=(\Psi-\mathrm{Ne})$ & $\mathrm{Al}^{+2}=(\Psi-\mathrm{Na})$ & $\mathrm{Al}^{+1}=(\Psi-\mathrm{Mg})$ & $\mathrm{Al}^{0}$ & $\mathrm{Al}^{-1}=(\Psi-\mathrm{Si})$ & $\mathrm{Al}^{-2}=(\Psi-\mathrm{P})$ & $\mathrm{Al}^{-3}=(\Psi-\mathrm{S})$ \\
$\mathrm{V}^{+3}=(\Psi-\mathrm{Ca})$ & $\mathrm{V}^{+2}=(\Psi-\mathrm{Sc})$ & $\mathrm{V}^{+1}=(\Psi-\mathrm{Ti})$ & $\mathrm{V}^{0}$ & $\mathrm{~V}^{-1}=(\Psi-\mathrm{Cr})$ & $\mathrm{V}^{-2}=(\Psi-\mathrm{Mn})$ & $\mathrm{V}^{-3}=(\Psi-\mathrm{Fe})$ \\
\hline
\end{tabular}

$\left(\mathrm{Li}^{+1}\right)_{3}\left[\mathrm{Al}^{-1}\left(\mathrm{~N}^{-1}\right)_{2}\right]$ or $(\Psi-\mathrm{He})_{3}(\Psi-$ $\mathrm{Si})(\Psi-\mathrm{O})_{2}$ (Table 2): this pseudocompound would then be expected to adopt the tetrahedral structure of one of the phases of elemental $\mathrm{Si}$, which would explain why the $\mathrm{Al}$ atom $(\Psi-\mathrm{Si})$ occupies the $16 c$ site of the structure.

Effectively, the $\mathrm{Al}^{-1}(\Psi-\mathrm{Si})$ atoms form the expected four-connected skeleton and the $\left[\mathrm{AlN}_{2}\right]^{-3}$ substructure becomes a $\left(\Psi-\mathrm{SiO}_{2}\right)$-like network of $\mathrm{AlN}_{4}$ tetrahedra, sharing all four corners, as found in most structural variants of silica. The result is that this

2.1.1. $\mathbf{L i}_{3} A \mathbf{A l N}_{2}$. The structure of $\mathrm{Li}_{3} \mathrm{AlN}_{2}$ was reported exactly 60 years ago by Juza \& Hund (1948). It can be analysed in the light of both the Zintl (1934) and Klemm (1958) concepts, in terms of which, various electron redistributions are allowed, provided that the overall electron count remains the same. Table 2 summarizes some of the possible redistributions for those species relevant to the present work.

Case 1: For example, if the formula $\mathrm{Li}_{3} \mathrm{AlN}_{2}$ were to be expressed in the usual ionic form, it would be written as $\left(\mathrm{Li}^{1+}\right)_{3}\left[\mathrm{AlN}_{2}\right]^{3-}$, i.e. $3 \mathrm{Li}^{1+}$ cations and the $\left[\mathrm{AlN}_{2}\right]^{3-}$ anion. If, then, two $\mathrm{Li}$ atoms were to donate two valence electrons to the two $\mathrm{N}$ atoms, converting them into two $(\Psi-\mathrm{O})$ atoms, and the third $\mathrm{Li}$ atom transferred its electron to the $\mathrm{Al}$ atom, converting it into $(\Psi-\mathrm{Si})$, the formal outcome would be may be regarded as Al-stuffed anti-bixbyite $\left(\mathrm{Li}_{3} \mathrm{~N}_{2}\right)$, with the substructure shown in Fig. 3 (Niewa et al., 2003). This feature is also in agreement with the 'general principle' deduced in the recent work of Vegas \& García-Baonza (2007), by which atoms try to form pseudo-structures characteristic of their group 14 isoelectronic counterparts.

Case 2: The structure can accommodate a second interpretation (Table 2). If the Zintl-Klemm concept were applied in the opposite direction, the $\mathrm{Al}$ atom would transfer its three valence electrons to $\mathrm{Li}$ forming three $\mathrm{Li}^{-1}$ species which then become isoelectronic with three $(\Psi-\mathrm{Be})$ : this would leave an [AlN $]^{+3}$ component made up of $\mathrm{Al}^{+3}$ and $\left(\mathrm{N}^{0}\right)_{2} \cdot \mathrm{Li}^{-1}$ is $(\Psi-\mathrm{Be}), \mathrm{Al}^{+3}$ is $(\Psi-\mathrm{Ne})$, and $\mathrm{N}^{0}$ remains as $\mathrm{N}$. The result is an $\mathrm{Al}^{+3}$-stuffed $\mathrm{Li}_{3} \mathrm{~N}_{2}$ or a hypothetical ( $\Psi$-Ne)-stuffed $\left(\Psi-\mathrm{Be}_{3} \mathrm{~N}_{2}\right)$ with the anti-bixbyite structure, like the real $\mathrm{Be}_{3} \mathrm{~N}_{2}$ compound (von Stackelberg \& Paulus, 1933). This description of bixbyite is illustrated in Fig. 3(a), where the $\mathrm{N}$ atoms (blue spheres) are arranged in an almost f.c.c. array. To see the deviation from the ideal f.c.c. array, we have represented in Fig. 4(a) a similar array of $\mathrm{O}$ atoms observed in $\mathrm{BPO}_{4}$ (Haines et al., 2003). Although the structures are not identical, they can be compared on the basis of the similar O subarray, and also because both compounds are formed by $\mathrm{XO}_{4}$ tetrahedra. In this compound (cristobalite-like), the $\mathrm{P}(\mathrm{B}) \mathrm{O}_{4}$ tetrahedra rotate in a continuous way when pressure is applied. At $50 \mathrm{GPa}$, the $\mathrm{O}$ array collapses, as in the chalcopyrite structure $(\mathrm{FeCuS})$, into an almost perfect f.c.c. arrangement, represented in Fig. 4(b) (Haines et al., 2003).

Case 3: Yet a third interpretation is possible (Table 2). This arises from the fact that the

\section{Figure 2}

The structures formed by four-connected networks, involving (II)-(VI), (III)-(V) and (IV)-(IV) pairs of atoms. (a) The structure of $\beta$-BeO. (b) Perspective view of the tetrahedral B network in $\mathrm{CrB}_{4}(\mathrm{Cr}$ atoms as green spheres). (c) The AlSi network in anorthite $\left(\mathrm{CaAl}_{2} \mathrm{Si}_{2} \mathrm{O}_{8}\right)$. Ca atoms are lodged in the octagonal tunnels. $(d)$ The AlP subarray of variscite $\mathrm{AlPO}_{4} \cdot 2 \mathrm{H}_{2} \mathrm{O}$. Note the similarity with the HP-Si of Fig. $1(b)$. The $\mathrm{Al}$ and $\mathrm{P}$ atoms form the puckered $\mathbf{4 . 8 ^ { 2 }}$ layers. $(e)$ The AlP subarray in metavariscite. Note the differences in the stacking of the $\mathbf{4 . 8 ^ { 2 }}$ layers in variscite and, at the same time, the similarities with both anorthite and $\beta$ $\mathrm{BeO}$. $(f)$ An isolated puckered $\mathbf{4 . 8 ^ { 2 }}$ layer to show its differences with the networks of HP-Si represented in Fig. 1(e). 
overall structure is essentially anti-fluorite, $\mathrm{N}_{2} M_{4}$, with $\mathrm{N} M_{8 / 4}$ cubes sharing edges, where $M_{4}=\mathrm{Li}_{3} \mathrm{Al}$. A well known example is $\mathrm{Mg}_{2} \mathrm{Si}$ in which $\mathrm{SiMg}_{8 / 4}$ cubes share edges (Owen \& Preston, 1924).

If we assume the transfer of two electrons from the two $\mathrm{N}$ atoms to the $\left[\mathrm{Li}_{3} \mathrm{Al}\right]$ array, the two $\mathrm{N}$ atoms each become $\mathrm{N}^{+1}$ or $(\Psi-\mathrm{C})$, while the $\left[\mathrm{Li}_{3} \mathrm{Al}\right]^{-2}$ array is electronically equivalent to $\left(\Psi-\mathrm{Li}_{3} \mathrm{P}\right)$ with its total of eight valence electrons for the four cations. This pseudo-compound $\left(\Psi-\mathrm{Li}_{3} \mathrm{P}\right)$ is then electronically equivalent to either $\left(\Psi-\mathrm{Mg}_{4}\right)$ or $\left(\Psi-\mathrm{Be}_{4}\right)$. Consequently, the compound $\mathrm{Li}_{3} \mathrm{AlN}_{2}$ would be formulated as the hypothetical ( $\left.\Psi-\mathrm{Li}_{3} \mathrm{PC}_{2}\right)$, electronically equivalent to $\left(\Psi-\mathrm{Mg}_{4} \mathrm{Si}_{2}\right)$ - the real anti-fluorite is $\mathrm{Mg}_{2} \mathrm{Si}$ (Owen \& Preston, 1924). However, this structure is no longer a stuffed anti-bixbyite. On the other
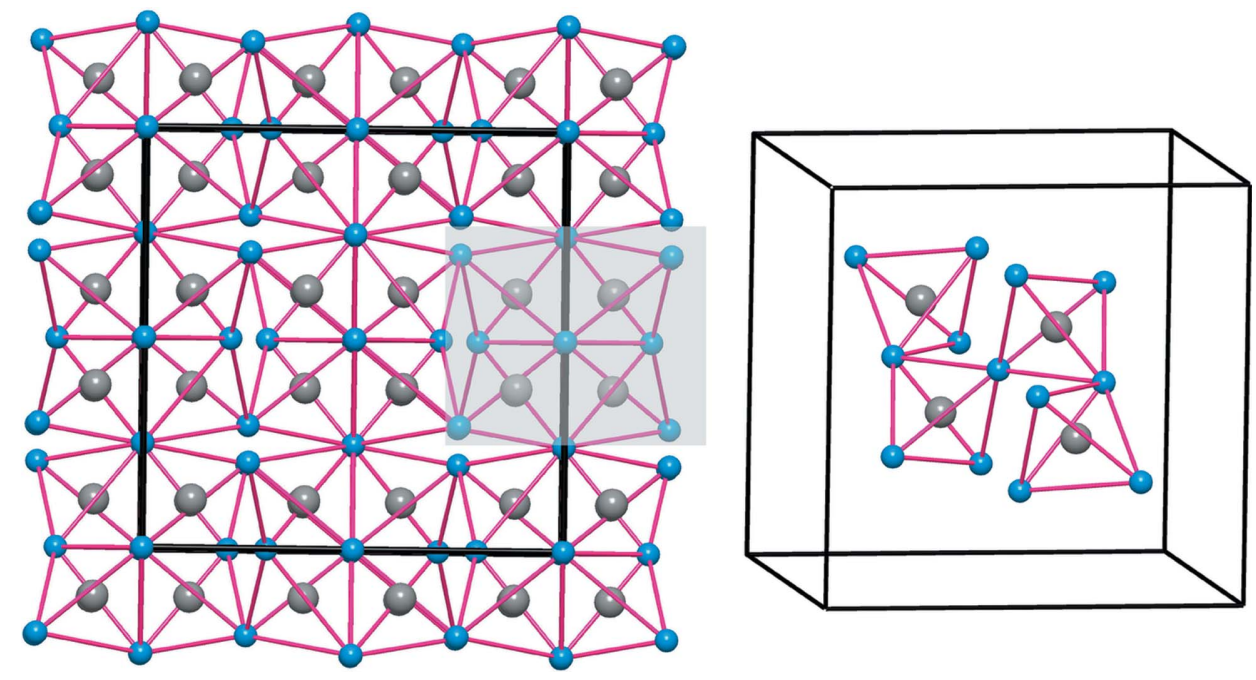

Figure 3

(a) The AlN $\mathrm{Al}_{2}$ substructure of the stuffed bixbyite $\mathrm{Li}_{3} \mathrm{AlN}_{2}$ formed by a three-dimensional network of AlN tetrahedra which share all corners. $(b)$ Detail of the four central tetrahedra to show their connectivity.

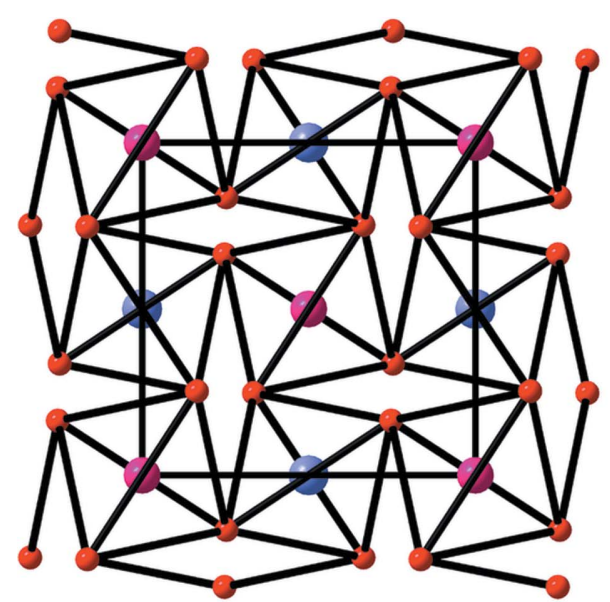

(a)

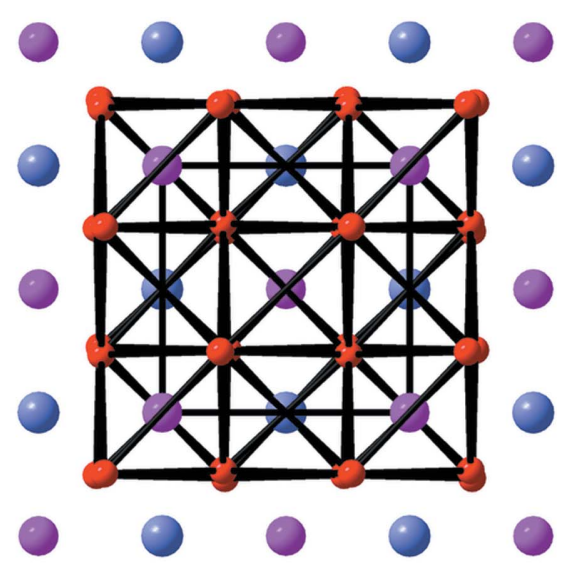

(b)
Figure 4

(a) The structure of $\mathrm{BPO}_{4}(I \overline{4})$ at $6.1 \mathrm{GPa}$, projected on the $a b$ plane. It is cristobalite-like and, under pressure, undergoes a continuous tilting of the $\mathrm{B}(\mathrm{P}) \mathrm{O}_{4}$ tetrahedra up to collapse, at $50 \mathrm{GPa}$, into an almost regular f.c.c. array of the $\mathrm{O}$ atoms represented in $(b)$. This final step corresponds to the chalcopyrite structure of $\mathrm{CuFeS}_{2}$. Note that the rhombs seen in $(a)$ are equivalent to those described in Fig. 2(a). In this continuous tilting of tetrahedra, the cation array BP remains as a blende-type structure. hand, the hypothetical $\left(\Psi-\mathrm{Li}_{3} \mathrm{PC}_{2}\right)$ compound could be described as a hypothetical, phosphorus-stuffed $\mathrm{Li}_{3} \mathrm{C}_{2}$ with the anti-bixbyite type structure.

The Zintl-Klemm concept can account for even more seudo-structures derived from $\mathrm{Li}_{3} \mathrm{AlN}_{2}$.

Case 4: By assuming that two $\mathrm{Li}$ atoms donate $2 e^{-}$to the third $\mathrm{Li}$ atom to give $\left(\mathrm{Li}^{+1}\right)_{2}\left[\mathrm{Li}^{-2} \mathrm{AlN}_{2}\right]^{-2}, \mathrm{Li}^{-2}$ would convert into $(\Psi-\mathrm{B})$, the anion becoming $\Psi$ - $\left[\mathrm{BAlN}_{2}\right]$. We must recall that both AIN and BN (III-V compounds) form blende-type structures (Wakatsuki et al., 1972) that are implicit in $\mathrm{Li}_{3} \mathrm{AlN}_{2}$, i.e. in its constituent nitrides $\mathrm{Li}_{3} \mathrm{~N}$ and $\mathrm{AlN}$ (see Fig. 5b). When all the Li atoms (donors and acceptors) are drawn (Fig. 4b), generated structure is a unit cell of a distorted fluorite, as was shown in Fig. 5. If four of the six Li atoms (the donors) were eliminated, the blende-type pseudo-array, of the formula ( $\Psi$ $\mathrm{LiAlN}_{2}$ ), would become evident, as seen in Fig. 6.

A final comment should be made on the $\mathrm{N}$ array. It has been shown (Figs. 3 and 5) that $\mathrm{N}$ atoms form a slightly distorted f.c.c. array, as do the indium atoms in $\mathrm{In}_{2} \mathrm{O}_{3}$ (Ramos-Gallardo \& Vegas, 1995). If we assume that all 6 electrons from $\left[\mathrm{Li}_{3} \mathrm{Al}\right]$ are transferred from these cations to form two nitride $\mathrm{N}^{3-}$ anions, the latter would behave as $(\Psi-\mathrm{Ne})$. The distorted f.c.c. unit cells of $\mathrm{N}$ atoms have dimensions varying from 4.82 to $4.89 \AA$ (mean $4.85 \AA$ ). This value is close to that of the unit cell of elemental $\mathrm{Ne}$, also f.c.c., with $a \simeq 4.50 \AA$. The $\mathrm{N}-\mathrm{N}$ distances, in the partial $\mathrm{LiAlN}_{2}$ array, range from 3.11 to $3.14 \AA$, close to the $\mathrm{Ne}-\mathrm{Ne}$ distances (3.18 $\AA$ ) in elemental Ne. Thus, the Ne structure can also be recognized in $\mathrm{Li}_{3} \mathrm{AlN}_{2}$ (see Fig. 5).

This last compound provides a nice example of how the location of atoms in different structural sites is not only determined by their relative atomic sizes, but also by their pseudo-electronic configurations. It could be said that such compounds highlight the unequivocal relationship existing between composition and structure which was postulated by Vegas \& García-Baonza (2007).

2.1.2. $\quad \mathbf{L i}_{3}\left[\left(M^{I \mathbf{V}}\right)_{0.67} \mathbf{L i}_{0.33}\right] \mathbf{N}_{\mathbf{2}}$. Case 5: The compounds, $\mathrm{Li}_{3}\left[\left(M^{\mathrm{IV}}\right)_{0.67} \mathrm{Li}_{0.33}\right] \mathrm{N}_{2}$, follow a 
similar pattern. Here, the $16 c$ site of space group $I a \overline{3}$ is randomly occupied by $M^{\mathrm{IV}}(\mathrm{Ge})$ and $\mathrm{Li}$ atoms, with reported population parameters of 0.67 and 0.33 for $M^{\mathrm{IV}}$ and $\mathrm{Li}$, respectively. The reader can readily recognize that this composition is equivalent to the presence of an atom with three valence electrons, like $\mathrm{Al}$ in $\mathrm{Li}_{3} \mathrm{AlN}_{2}$ (Juza \& Hund, 1948). Thus, the fractional occupation factors are explained by the need for satisfying the four valence electrons of the $2 / 3$ $M^{\mathrm{IV}}$ plus $1 / 3 \mathrm{Li}$ atoms located at $16 c$. Thus, two of the three $\mathrm{Li}$ atoms located at $48 e$ transfer two electrons to the $\mathrm{N}$ atoms, converting them into two $(\Psi-\mathrm{O})$. The third $\mathrm{Li}$ atom at $48 e$ (16 $\mathrm{Li}$ atoms) donates its valence electron to the $\mathrm{Li}_{0.33}$ located at $16 c$ to generate $\left(\mathrm{Li}^{+1}\right)_{3}\left(\mathrm{Li}^{-3}\right)_{0.33}\left(M^{\mathrm{IV}}\right)_{0.67}^{0}\left(\mathrm{~N}^{-1}\right)_{2}$, with the electronically balanced charge distribution of $\mathrm{Li}_{3} \mathrm{AlN}_{2}$. This transfer of three electrons to the core $\mathrm{Li}$ atom converts it into ( $\Psi$-C), hence forming, together with the $M^{\mathrm{IV}}$ atoms, a fourconnected net. Now we are able to explain two structural features: on the one hand, why the Li atoms occupy one third of the $16 c$ site and not another position such as $8 b$. The reason is that this is the only way of achieving the observed fourconnected network of $\gamma$-Ge. We can also explain why the $M^{\mathrm{IV}}$ atoms are precisely located at that site and not partially

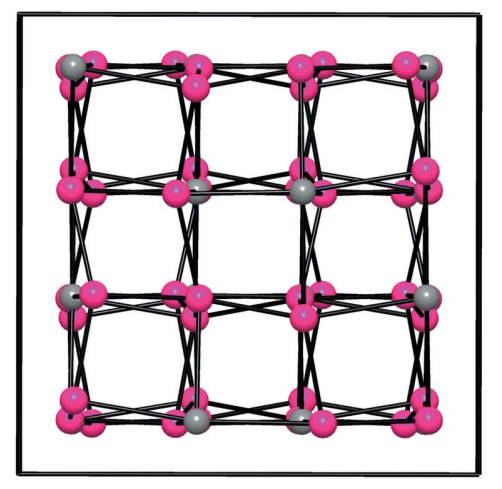

(a)
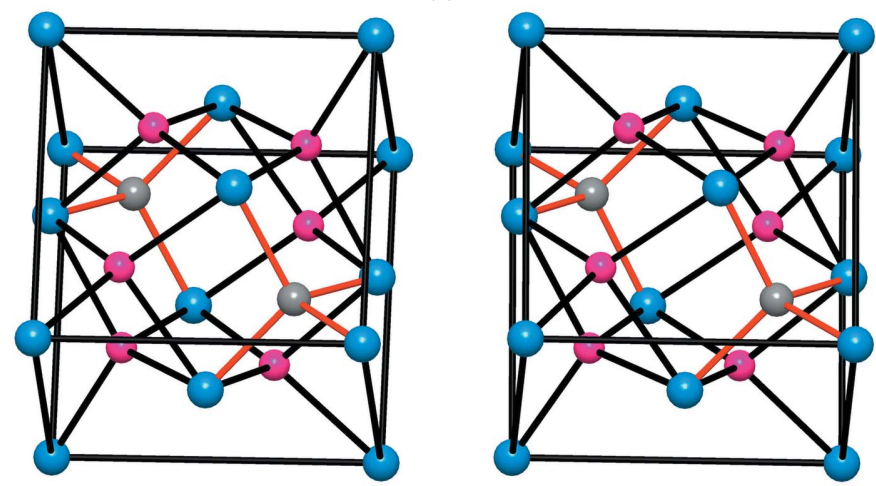

(b)

Figure 5

(a) The $\mathrm{Li}_{3} \mathrm{Al}(\mathrm{Ge})$ subarray projected on the $a b$ plane. They form a distorted simple cubic array. As in $\mathrm{CaF}_{2}$, the $\mathrm{N}$ atoms (omitted) occupy alternate cubes of this $\mathrm{AlLi}_{3}$ array. The $\mathrm{N}$ atoms form, in turn, a distorted f.c.c. structure like In atoms in $\operatorname{In}_{2} \mathrm{O}_{3}$. (b) Stereopair representing a distorted face-centered cube of $\mathrm{N}$ atoms (blue spheres) with all the tetrahedral holes occupied by $\mathrm{Li}$ (pink) and $\mathrm{Al}(\mathrm{Ge})$ (grey) atoms. The structure is a distorted fluorite-like array where the ZnS-blende structure is also implicit. Note the special location of $\mathrm{Ge}(\mathrm{Al})$ atoms. occupying the alternative $48 e$ positions: in this latter site, the Ge skeleton could not be formed.

2.1.3. $\mathbf{L i}_{6}\left[\boldsymbol{M}^{\mathrm{V}} \mathbf{L i}\right] \mathbf{N}_{\mathbf{4}}\left(\boldsymbol{M}^{\mathbf{V}}=\mathbf{V}, \mathbf{N b}, \mathrm{Ta}\right)$. Case 6: Like $\mathrm{Li}_{3} \mathrm{AlN}_{2}$ and $\mathrm{Li}_{3}\left[\mathrm{Li}_{0.33} \mathrm{Ge}_{0.67}\right] \mathrm{N}_{2}$, the EZKC, when applied to this compound, predicts that it also involves four-connected nets. For example, at one analytical level we can suppose that four $\mathrm{Li}$ atoms donate four electrons to the $\mathrm{N}$ atoms, converting them into $(\Psi-\mathrm{O})$, and that the two remaining Li atoms transfer two additional electrons to the $\left[M^{\mathrm{V}} \mathrm{Li}\right]$ set, converting it into either $(\Psi-[\mathrm{III}-\mathrm{V}])$ or $(\Psi-[\mathrm{II}-\mathrm{VI}])$ pairs, forming fourconnected nets. The $\left[M^{\mathrm{V}} \mathrm{Li}\right]^{-2}$ substructure is represented in Fig. 7. Here, the $M^{\mathrm{V}}$ and $\mathrm{Li}$ atoms are not distributed at random, as in the $16 c$ site of $I a \overline{3}$, but they are ordered into two sets on $8 c$ sites of the subgroup $P a \overline{3}$ from which the bodycentering operation in $I a \overline{3}$ has been dropped.

At a slightly deeper level, the outcome of these electron transfers (see Table 2) is the compound $\left(\mathrm{Li}^{+1}\right)_{3}\left(\mathrm{Li}^{-3}\right)_{0.5}\left(M^{+1}\right)_{0.5}\left(\mathrm{~N}^{-1}\right)_{2}$, which is isostructural with the four-connected network of the tetrahedral pseudo-compound $(\Psi-\mathrm{He})_{3}\left(\Psi-\mathrm{C}_{0.5} \mathrm{Ti}_{0.5}\right)(\Psi-\mathrm{O})_{2}$ (assuming that $\left.M^{+1}=\mathrm{V}^{+1}\right)$, i.e. the hypothetical $\left(\Psi-\mathrm{He}_{3}\left[\mathrm{C}_{0.5} \mathrm{Ti}_{0.5}\right] \mathrm{O}_{2}\right)$, a hypothetical ' $\mathrm{C} / \mathrm{Ti}$-stuffed $\mathrm{He}_{3} \mathrm{O}_{2}$ '. Again, we have what is essentially a $\mathrm{V} / \mathrm{Li}$-stuffed $\mathrm{Li}_{3} \mathrm{~N}_{2}$.

The discussion about the different structures which co-exist in these stuffed bixbyite-type compounds can be extended to these compounds. The lack of isostructural compounds containing Group 15 elements ( $\mathrm{P}, \mathrm{As}, \mathrm{Sb}$ and $\mathrm{Bi}$ ) is noteworthy. However, we must recall the similar chemical and structural behaviors of vanadates and niobates on one hand, and phosphates and arsenates on the other. Moreover, if we assume that the $\left[M^{\mathrm{V}} \mathrm{Li}\right]^{-2}$ sub-array is formed by a ( $\Psi$-[III-V]) pair, it must be strongly related to [AlP] substructures like those of $\mathrm{AlPO}_{4}$, represented in Fig. 2. Compare Fig. 2(d) of variscite with Fig. 7. The remaining co-existing structures can be easily deduced, as with $\mathrm{Li}_{3} \mathrm{AlN}_{2}$.

Table 3 attempts to collect and summarize all the foregoing discussion of the Zintl-Klemm analyses.
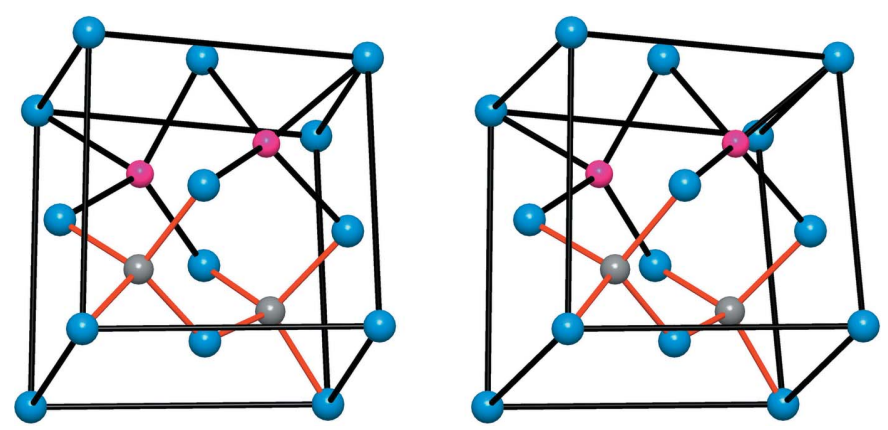

Figure 6

A fragment of the structure of $\mathrm{Li}_{3} \mathrm{AlN}_{2}$. The stereopair shows a distorted f.c.c. unit cell of $\mathrm{N}$ atoms (blue spheres) with half of the tetrahedral holes occupied by two $\mathrm{Al}$ atoms (grey spheres) and two Li atoms ( $\Psi$-B) (pink spheres). All together they form a unit cell of the blende-type $\mathrm{AlBN}_{2}$ (a III-V compound). The remaining four $\mathrm{Li}$ atoms, considered as donors, have been omitted. The distorted f.c.c. array of $\mathrm{N}$ atoms and the unit cell of elemental $\mathrm{Ne}$ have similar dimensions. 
Table 3

Summary of various electron redistributions discussed in the text.

\begin{tabular}{|c|c|c|c|}
\hline Case & $\begin{array}{l}\text { Normal compound } \\
\text { Atomic species } \\
\text { Phase description }\end{array}$ & $\begin{array}{l}\text { Zintl-Klemm notation } \\
\text { Electron redistribution }\end{array}$ & $\begin{array}{l}\text { Pseudo-phase } \\
\text { Phase description }\end{array}$ \\
\hline 1 & $\begin{array}{l}\mathrm{Li}_{3} \mathrm{AlN}_{2} \\
\left(\mathrm{Li}^{0}\right)_{3} \mathrm{Al}^{0}\left(\mathrm{~N}^{0}\right)_{2} \\
\text { 'Al-stuffed } \mathrm{Li}_{3} \mathrm{~N}_{2} \text { anti-bixbyite' }\end{array}$ & $\begin{array}{l}\left(\mathrm{Li}^{+1}\right)_{3}\left[\mathrm{Al}^{-1}\left(\mathrm{~N}^{-1}\right)_{2}\right] \\
(\Psi-\mathrm{He})_{3}(\Psi-\mathrm{Si})(\Psi-\mathrm{O})_{2}\end{array}$ & $\begin{array}{l}\left(\Psi-\mathrm{He}_{3} \mathrm{SiO}_{2}\right) \\
\text { 'Si-stuffed } \mathrm{He}_{3} \mathrm{O}_{2} \text { anti-bixbyite' }\end{array}$ \\
\hline 2 & $\begin{array}{l}\mathrm{Li}_{3} \mathrm{AlN}_{2} \\
\left(\mathrm{Li}^{0}\right)_{3} \mathrm{Al}^{0}\left(\mathrm{~N}^{0}\right)_{2}\end{array}$ & $\begin{array}{l}\left(\mathrm{Li}^{-1}\right)_{3} \mathrm{Al}^{+3}\left(\mathrm{~N}^{0}\right)_{2} \\
(\Psi-\mathrm{Be})_{3}(\Psi-\mathrm{Ne})\left(\mathrm{N}^{0}\right)_{2}\end{array}$ & $\begin{array}{l}\left(\Psi-\mathrm{Be}_{3} \mathrm{NeN}_{2}\right) \\
\text { 'Ne-stuffed } \mathrm{Be}_{3} \mathrm{~N}_{2} \text { anti-bixbyite' }\end{array}$ \\
\hline 3 & $\begin{array}{l}\mathrm{Li}_{3} \mathrm{AlN}_{2} \\
\left(\mathrm{Li}^{0}\right)_{3} \mathrm{Al}^{0}\left(\mathrm{~N}^{0}\right)_{2}\end{array}$ & $\begin{array}{l}{\left[\mathrm{Li}_{3} \mathrm{Al}\right]^{-2}\left(\mathrm{~N}^{+1}\right)_{2}} \\
\left(\Psi-\mathrm{Li}_{3} \mathrm{P}\right)(\Psi-\mathrm{C})_{2}\end{array}$ & $\begin{array}{l}\left(\Psi-\mathrm{Li}_{3} \mathrm{PC}_{2}\right) \equiv\left(\Psi-\mathrm{Mg}_{4} \mathrm{Si}_{2}\right) \\
\text { 'P-stuffed } \mathrm{Li}_{3} \mathrm{C}_{2} \text { anti-bixbyite' }\end{array}$ \\
\hline 4 & $\begin{array}{l}\mathrm{Li}_{3} \mathrm{AlN}_{2} \\
\left(\mathrm{Li}^{0}\right)_{3} \mathrm{Al}^{0}\left(\mathrm{~N}^{0}\right)_{2}\end{array}$ & $\begin{array}{l}\left(\mathrm{Li}^{+1}\right)_{2}\left[\mathrm{Li}^{-2} \mathrm{Al}^{0}\left(\mathrm{~N}^{0}\right)_{2}\right] \\
(\Psi-\mathrm{He})_{2}\left[(\Psi-\mathrm{B}) \mathrm{Al}^{0}\right]\left(\mathrm{N}^{0}\right)_{2}\end{array}$ & $\begin{array}{l}(\Psi-\mathrm{He})_{2}\left(\Psi-\mathrm{BAlN}_{2}\right) \\
\text { 'Blende' }\end{array}$ \\
\hline 5 & $\begin{array}{l}\mathrm{Li}_{3}\left(\mathrm{Ge}_{0.667} \mathrm{Li}_{0.333}\right) \mathrm{N}_{2} \\
\left(\mathrm{Li}^{0}\right)_{3}\left[\left(\mathrm{Ge}^{0}\right)_{0.667}\left(\mathrm{Li}^{0}\right)_{0.333}\right]\left(\mathrm{N}^{0}\right) \\
\text { 'Ge/Li-stuffed } \mathrm{Li}_{3} \mathrm{~N}_{2} \text { anti-bixbyite' }\end{array}$ & $\begin{array}{l}\left(\mathrm{Li}^{+1}\right)_{3}\left[\left(\mathrm{Li}^{-3}\right)_{0.333}\left(\mathrm{Ge}^{0}\right)_{0.667}\right]\left(\mathrm{N}^{-1}\right)_{2} \\
(\Psi-\mathrm{He})_{3}\left[(\Psi-\mathrm{C})_{0.333} \mathrm{Ge}_{0.667}\right](\Psi-\mathrm{O})_{2}\end{array}$ & $\begin{array}{l}\left(\Psi-\mathrm{He}_{3} \mathrm{Si}_{0.333} \mathrm{Ge}_{0.667} \mathrm{O}_{2}\right) \\
\text { 'Si/Ge-stuffed } \mathrm{He}_{3} \mathrm{O}_{2} \text { anti-bixbyite' }\end{array}$ \\
\hline 6 & $\begin{array}{l}\mathrm{Li}_{6}\left[\mathrm{~V}^{\mathrm{V}} \mathrm{Li}\right] \mathrm{N}_{4} \\
\left(\mathrm{Li}^{0}\right)_{6}\left[\mathrm{~V}^{0} \mathrm{Li}^{0}\right]\left(\mathrm{N}^{0}\right)_{4} \\
\mathrm{~V} / \mathrm{Li} \text {-stuffed } \mathrm{Li}_{3} \mathrm{~N}_{2} \text { anti-bixbyite }\end{array}$ & $\begin{array}{l}\left(\mathrm{Li}^{+1}\right)_{3}\left[\left(\mathrm{Li}^{-3}\right)_{0.5}\left(M^{+1}\right)_{0.5}\right]\left(\mathrm{N}^{-1}\right)_{2} \\
(\Psi-\mathrm{He})_{3}\left[\left(\Psi-\mathrm{C}_{0.5} \mathrm{Ti}_{0.5}\right)\right](\Psi-\mathrm{O})_{2}\end{array}$ & $\begin{array}{l}\Psi-\mathrm{He}_{3}\left(\mathrm{C}_{0.5} \mathrm{Ti}_{0.5}\right) \mathrm{O}_{2} \\
\text { 'Ti/C-stuffed } \mathrm{He}_{3} \mathrm{O}_{2} \text { anti-bixbyite' }\end{array}$ \\
\hline
\end{tabular}

hold true for the presence of any atom different in kind from the predominant atomic species forming a lattice.

In the context of an antibixbyite structure (space group $I a \overline{3})$ such as magnesium nitride (a cation-deficient, anti-fluoriterelated compound of the general formula $M_{3} \square_{M} \mathrm{~N}_{2}$, where $\square_{M}$ is a vacancy in the cation sublattice), what we now might call an anti$\mathrm{CD}$ is described as an octahedron of $M X_{4}$ tetrahedra sharing corners to enclose an empty tetrahedron $\left(\square_{M} X_{4}\right)$ or, alternatively, an empty tetrahedron, $\left(\square_{M} X_{4}\right.$ ), sharing all six edges with $M X_{4}$ tetrahedra, forming a $\square_{M^{-}}$

\subsection{Coordination-defect (CD) approach}

The CD theory was proposed originally by Martin (1974) to describe the structures of the many well known, anion-deficient, fluorite-related compounds, of which bixbyite is but one example. He proposed that the anion vacancies in such structures were not simply isolated point defects, randomly distributed throughout the fluorite lattice, but rather that each vacancy was strongly coordinated by its nearest and nextnearest neighbours, four cations and six anions, to generate an octahedral structural entity, the $\mathrm{CD}$, of considerable thermodynamic and structural stability. Indeed this concept can be extended to other non-fluorite structures of different symmetry for it can be argued that the same principle would

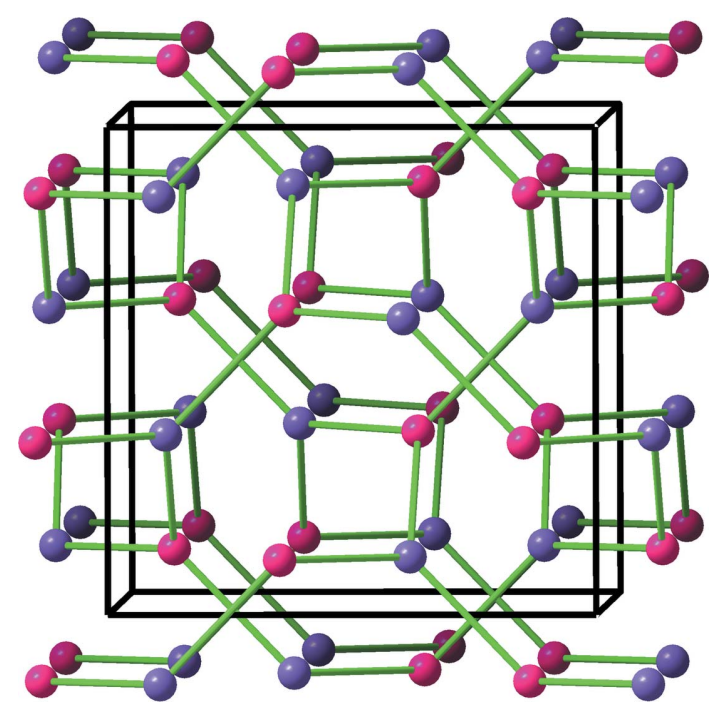

Figure 7

The [VLi] skeleton in $\mathrm{Li}_{6}[\mathrm{LiV}] \mathrm{N}_{4}$ similar to both the $\mathrm{Al}(\Psi-\mathrm{Si})$-array in $\mathrm{Li}_{3} \mathrm{AlN}_{2}$ and the structure of $\gamma-\mathrm{Si}$, represented in Fig. 1. Li and $\mathrm{V}$ atoms are ordered occupying different positions of the $8 c$ site in the space group $\mathrm{Pa} \overline{3}$. Each atom connects to four unlike atoms. One of these bonds has been omitted to show the two interpenetrating three-connected subsets. centred octahedron represented as $M_{6} \square_{M} X_{4}$. This is shown in Fig. 8, comprising a central tetrahedral core with six peripheral tetrahedra.

Incorporated into the anti-fluorite-type structure, and therefore taking account of the sharing of all tetrahedral edges such that every $X$ atom is common to eight tetrahedra, the anti-CD composition becomes $\square_{M} X_{4 / 8}\left(M X_{4 / 8}\right)_{6}$ or $X_{7} M_{12}\left(\square_{M}\right)_{2}$. Moreover, analogous to the bixbyite case, each peripheral $M X_{4 / 8}$ tetrahedron of the anti-CD in the antibixbyite structure is common to another anti-CD, and the antibixbyite composition expressed in the anti-CD format is $\square_{M} X_{4 / 8}\left(M X_{4 / 8}\right)_{6 / 2}$ or $M_{3} \square_{M} X_{2}$. The $\square_{M}$ site is the $16 c$ site of $I a \overline{3}$, which is also the site occupied by $\mathrm{Si}$ in $\gamma$-Si. If, now, this vacancy can accommodate a pseudo-Si atom, we obtain the compound $M_{3}(\Psi-\mathrm{Si}) X_{2}$, whose counterparts are $\mathrm{Li}_{3} \mathrm{AlN}_{2}$ and $\mathrm{Li}_{3} \mathrm{ScN}_{2}$, with a truly 'stuffed' anti-bixbyite structure, the $\mathrm{Al}$

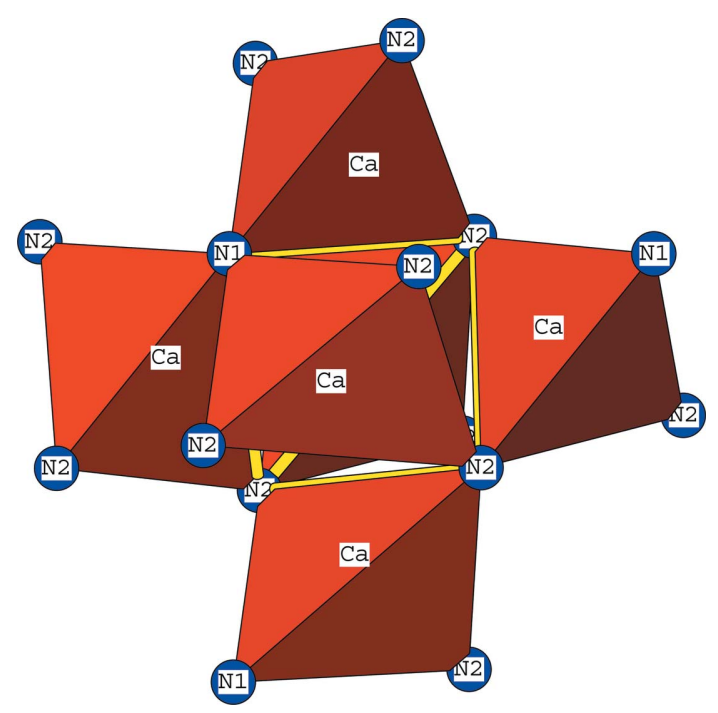

Figure 8

The anti-CD in $\mathrm{Ca}_{3} \mathrm{~N}_{2}$. The $\square_{M} X_{4}$ tetrahedron at the centre is drawn in yellow outlines. The six peripheral $\mathrm{CaN}_{4}$ tetrahedra are drawn as such in red. 
Table 4

CD representations for cases 1-3.

\begin{tabular}{|c|c|c|c|c|}
\hline \multirow[b]{2}{*}{ Case } & \multirow[b]{2}{*}{ Zintl-Klemm } & \multicolumn{3}{|c|}{ Anti-CD representation } \\
\hline & & Core tetrahedron & Peripheral tetrahedron & $\begin{array}{l}\text { Overall formula } \\
\text { Pseudo-compound }\end{array}$ \\
\hline 1 & $\left(\mathrm{Li}^{+1}\right)_{3} \mathrm{Al}^{-1}\left(\mathrm{~N}^{-1}\right)_{2}$ & {$\left[\mathrm{Al}^{-1}\left(\mathrm{~N}^{-1}\right)_{4 / 8}\right]^{-1.5}$} & {$\left[\mathrm{Li}^{+}\left(\mathrm{N}^{-1}\right)_{4 / 8}\right]^{+0.5}$} & $\begin{array}{l}{\left[\mathrm{Al}^{-1}\left(\mathrm{~N}^{-1}\right)_{4 / 8}\right]^{-1.5}\left\{\left[\mathrm{Li}^{+1}\left(\mathrm{~N}^{-1}\right)_{4 / 8}\right]^{+0.5}\right\}_{6 / 2}} \\
\left(\Psi-\mathrm{He}_{3} \mathrm{SiO}_{2}\right)\end{array}$ \\
\hline 2 & $\left(\mathrm{Li}^{-1}\right)_{3} \mathrm{Al}^{+3}\left(\mathrm{~N}^{0}\right)_{2}$ & {$\left[\mathrm{Al}^{+3}\left(\mathrm{~N}^{0}\right)_{4 / 8}\right]^{+3}$} & {$\left[\mathrm{Li}^{-1}\left(\mathrm{~N}^{0}\right)_{4 / 8}\right]^{-1}$} & $\begin{array}{l}{\left[\mathrm{Al}^{+3}\left(\mathrm{~N}^{0}\right)_{4 / 8}\right]^{+3}\left\{\left[\mathrm{Li}^{-1}\left(\mathrm{~N}^{0}\right)_{4 / 8}\right]^{-1}\right\}_{6 / 2}} \\
\left(\Psi-\mathrm{Be}_{3} \mathrm{NeN}_{2}\right)\end{array}$ \\
\hline 3 & {$\left[\mathrm{Li}_{3} \mathrm{Al}\right]^{-2}\left(\mathrm{~N}^{+1}\right)_{2}$} & {$\left[\mathrm{Al}^{-2}\left(\mathrm{~N}^{+1}\right)_{4 / 8}\right]^{-1.5}$} & {$\left[\mathrm{Li}^{0}\left(\mathrm{~N}^{+1}\right)_{4 / 8}\right]^{+0.5}$} & $\begin{array}{l}{\left[\mathrm{Al}^{-2}\left(\mathrm{~N}^{+1}\right)_{4 / 8}\right]^{-1.5}\left\{\left[\mathrm{Li}^{0}\left(\mathrm{~N}^{+1}\right)_{4 / 8}\right]_{6 / 2}\right\}^{+1.5}} \\
\left(\Psi-\mathrm{Li}_{3} \mathrm{PC}_{2}\right)\end{array}$ \\
\hline
\end{tabular}

overall $\left(\Psi-\mathrm{Be}_{3} \mathrm{NeN}_{2}\right)$ - a hypothetical, neon-stuffed $\left(\Psi-\mathrm{Be}_{3} \mathrm{~N}_{2}\right)$, as described earlier.

Case 3: The third interpretation involves the transfer of two electrons from the two $\mathrm{N}$ atoms to the $\mathrm{Al}$ so that the subarray becomes $\left[\mathrm{Al}^{-2}\left(\mathrm{~N}^{+1}\right)_{2}\right]^{0}$, which is electronically equivalent to $(\Psi-\mathrm{P})(\Psi-\mathrm{C})_{2}$. The CD formulation becomes $\left[\mathrm{Al}^{-2}\left(\mathrm{~N}^{+1}\right)_{4 / 8}\right]^{-1.5}\left\{\left[\mathrm{Li}^{0}\left(\mathrm{~N}^{+1}\right)_{4 / 8}\right]_{6 / 2}\right\}^{+1.5}$, with the corresponding pseudo-CD being $\left[(\Psi-\mathrm{P})(\Psi-\mathrm{C})_{4 / 8}\right]\left[\mathrm{Li}^{0}(\Psi-\mathrm{C})_{4 / 8}\right]_{6 / 2}$ or $\left(\Psi-\mathrm{Li}_{3} \mathrm{PC}_{2}\right)$, i.e. a phospho-carbon

and Sc atoms occupying respectively the tetrahedrally coordinated, vacant cation sites of the actual anti-bixbyite structure.

In the case of $\mathrm{Li}_{3} \mathrm{AlN}_{2}$, and assuming the normal ionic charge assignments, the anti-CD core becomes the $\left[\mathrm{Al}^{3+}\left(\mathrm{N}^{3-}\right)_{4 / 8}\right]^{1.5+}$ tetrahedron, with $\mathrm{Al}$ occupying the antibixbyite cation vacancy, while each of the six peripheral antiCD tetrahedra in the overall structure is $\left[\left(\mathrm{Li}^{1+}\right)\left(\mathrm{N}^{3-}\right)_{4 / 8}\right]^{0.5-}$. In standard chemical usage, the overall anti-CD formula of $\mathrm{Li}_{3} \mathrm{AlN}_{2}$ is $\left.\left(\mathrm{AlN}_{4 / 8}\right)^{1.5+}\left[\left(\mathrm{LiN}_{4 / 8}\right)\right]_{6 / 2}\right]^{1.5-}$.

Case 1: We now apply the first of the above Zintl-Klemm interpretations of $\mathrm{Li}_{3} \mathrm{AlN}_{2}$, i.e. two $\mathrm{Li}$ atoms donate two valence electrons to the two $\mathrm{N}$ atoms converting them into ( $\Psi-\mathrm{O}$ ) atoms, the third $\mathrm{Li}$ atom transfers its electron to the $\mathrm{Al}$ atom, converting it into $(\Psi-\mathrm{Si})$. The formal outcome is $\left(\mathrm{Li}^{+1}\right)_{3} \mathrm{Al}^{-1}\left(\mathrm{~N}^{-1}\right)_{2}$ in the Zintl-Klemm notation. Here, $\mathrm{Li}^{+1}$ is $(\Psi-\mathrm{He}), \mathrm{Al}^{-1}$ and $\mathrm{N}^{-1}$ are $(\Psi-\mathrm{Si})$ and $(\Psi-\mathrm{O})$, respectively. The anti-CD formulation of this becomes $\left[\mathrm{Al}^{-1}\left(\mathrm{~N}^{-1}\right)_{4 / 8}\right]^{-1.5}$ as the core, the peripheral tetrahedra being $\left[\mathrm{Li}^{+1}\left(\mathrm{~N}^{-1}\right)_{4 / 8}\right]^{+0.5}$, with $\mathrm{Al}^{-1}$, i.e. ( $\Psi-\mathrm{Si}$ ), 'stuffing' the tetrahedral void, $\square_{M}$, in the anti-CD core. Each of the six peripheral tetrahedra of the anti$\mathrm{CD}$, with the formula $\left[\mathrm{Li}^{+1}\left(\mathrm{~N}^{-1}\right)_{4 / 8}\right]^{+0.5}$, is common to another such anti-CD, and has $\mathrm{Li}^{+1}$, with the $(\Psi-\mathrm{He})$ spherical electron configuration at its centre, coordinated by a tetrahedron of $\mathrm{N}^{-1}$ atoms, i.e. $(\Psi-\mathrm{O})$. The resulting pseudo-anti-CD representation of $\mathrm{Li}_{3} \mathrm{AlN}_{2}$ can now be written as $\left[\mathrm{Al}^{-1}\left(\mathrm{~N}^{-1}\right)_{4 / 8}\right]^{-1.5}$. $\left\{\left[\mathrm{Li}^{+1}\left(\mathrm{~N}^{-1}\right)_{4 / 8}\right]^{+0.5}\right\}_{6 / 2}$ or $\left.\left[(\Psi-\mathrm{Si})(\Psi-\mathrm{O})_{4 / 8}\right]\left[(\Psi-\mathrm{He})(\Psi-\mathrm{O})_{4 / 8}\right)\right]_{6 / 2}$, i.e. overall $\left(\Psi-\mathrm{SiO}_{2}\right)+3(\Psi-\mathrm{He})$ with the spherical eight-electron configuration. This is equivalent to $\left(\Psi-\mathrm{He}_{3} \mathrm{SiO}_{2}\right)$, i.e. a hypothetical ( $\Psi$-Si)-stuffed anti-bixbyite, in agreement with the conclusion reached in the previous section. In this CD description, we see that the CD core has an excess of electrons, while the core periphery has an equal electron deficit.

Case 2: The second interpretation applies the Zintl-Klemm concept in the opposite direction, with the $\mathrm{Al}$ atom transferring its three valence electrons to $\mathrm{Li}$ forming three $\mathrm{Li}^{-1}$ species, each of which is isoelectronic with $(\Psi-\mathrm{Be})$ and an $\left[\mathrm{Al}^{+3}\left(\mathrm{~N}^{0}\right)_{2}\right]^{+3}$ sub-structure yielding a $(\Psi$-Ne)-stuffed $\left(\Psi-\mathrm{Be}_{3} \mathrm{~N}_{2}\right)$, with the anti-bixbyite structure as in real $\mathrm{Be}_{3} \mathrm{~N}_{2}$ (von Stackelberg \& Paulus,1933). With this second set of electronic assignments, $\mathrm{Li}_{3} \mathrm{AlN}_{2}$ can be formulated as the anti-CD, $\left[\mathrm{Al}^{+3}\left(\mathrm{~N}^{0}\right)_{4 / 8}\right]^{+3}\left\{\left[\mathrm{Li}^{-1}\left(\mathrm{~N}^{0}\right)_{4 / 8}\right]^{-1}\right\}_{6 / 2}$. The pseudo-anti$\mathrm{CD}$ can now be written as $\left[(\Psi-\mathrm{Ne}) \mathrm{N}_{4 / 8}\right]\left[(\Psi-\mathrm{Be}) \mathrm{N}_{4 / 8}\right]_{6 / 2}$, i.e. stoichiometric analogue of $\mathrm{Li}_{3} \mathrm{AlN}_{2}$. Indeed it can be described as a hypothetical phosphorus-stuffed lithium carbide, $\mathrm{Li}_{3} \mathrm{PC}_{2}$ with the anti-bixbyite structure. These descriptions are summarized in Table 4.

Case 4: This case, discussed above, identifies the tetrahedral blende-type structures, $\mathrm{AlN}$ and $\mathrm{BN}$, that are implicit in $\mathrm{Li}_{3} \mathrm{AlN}_{2}$. Thus, the electron distribution $\left(\mathrm{Li}^{+1}\right)_{2}\left[\mathrm{Li}^{-2} \mathrm{AlN} \mathrm{N}_{2}\right]$, as quoted above, leads to the pseudo compound, $(\Psi-\mathrm{He})_{2}\left[(\Psi-\mathrm{B}) \mathrm{AlN}_{2}\right]$, confirming a blende-type anion which could be regarded as a $1: 1$ mixture of $(\Psi-\mathrm{He})(\Psi-\mathrm{BN})$ and $(\Psi-\mathrm{He})(\Psi-\mathrm{AlN})$.

Since the stoichiometry of blende-type structures is quite different from that of anti-bixbyite, the CD concept is no longer relevant. However, it is encouraging that the $C D$ formulations of the first three interpretations are completely consistent with those derived by employing the Zintl-Klemm concept.

Case 5: $\mathrm{Li}_{3}\left[\left(M^{\mathrm{IV}}\right)_{0.67} \mathrm{Li}_{0.33}\right] \mathrm{N}_{2}$. Apart from the disordered mix of $M^{\mathrm{IV}}$ and Li within the core tetrahedron, the treatment of this phase is the same as for $\mathrm{Li}_{3} \mathrm{AlN}_{2}$. This is summarized in Table 5 .

Case 6: In the case of the $\mathrm{Li}_{6}\left[M^{\mathrm{V}} \mathrm{Li}\right] \mathrm{N}_{4}$ compounds, because the set in the square brackets is strictly ordered, there will be two kinds of anti-CD tetrahedral core, $\left[\mathrm{LiN}_{4 / 8}\right]$ and $\left[M^{\mathrm{V}} \mathrm{N}_{4 / 8}\right]$, and just the one type of peripheral tetrahedron, $\left[\mathrm{LiN}_{4 / 8}\right]$. The composition of the compound $\mathrm{Li}_{6}\left[\mathrm{Li} M^{\mathrm{V}}\right] \mathrm{N}_{4}$ can also be written as $\mathrm{Li}_{3}\left[\mathrm{Li}_{0.5} M_{0.5}^{\mathrm{V}}\right] \mathrm{N}_{2}$. This ensures that the fractional population parameters associated with $\mathrm{Li}^{\mathrm{I}}$ and $M^{\mathrm{V}}(=\mathrm{V}, \mathrm{Nb}, \mathrm{Ta})$ continue to provide an electronically balanced charge distribution. As with $\mathrm{Li}_{3} \mathrm{AlN}_{2}$ and $\mathrm{Li}_{3}\left[\mathrm{Li}_{0.33} \mathrm{Ge}_{0.67}\right] \mathrm{N}_{2}$, the Zintl-Klemm concept, when applied to this compound, confirms that it also involves 4-connected nets. For example, if three electrons were transferred from $\mathrm{Li}_{3}$ to the two $\mathrm{N}$ and the single core-Li atom, the species $\left(\mathrm{Li}^{+1}\right)_{3}, \mathrm{Li}^{-1}$ in the core, and $\left(\mathrm{N}^{-1}\right)_{2}$ would result. If an additional electron were transferred from $M^{\mathrm{V}}$ to the core $\mathrm{Li}$ atom, the resulting compound would become $\left(\mathrm{Li}^{+1}\right)_{3}\left[\left(\mathrm{Li}^{-3}\right)_{0.5}\left(M^{+1}\right)_{0.5}\right]\left(\mathrm{N}^{-1}\right)_{2}$, which is isostructural with the tetrahedral pseudo-compound $(\Psi-\mathrm{He})_{3}\left[(\Psi-\mathrm{C})_{0.5^{-}}\right.$ $\left.\left(\Psi-M^{\mathrm{IV}}\right)_{0.5}\right](\Psi-\mathrm{O})_{2}$ and its four-connected tetrahedral network. If we rewrite this as $\left(\mathrm{Li}^{+1}\right)_{6}\left[\mathrm{Li}^{-3} M^{+1}\right]\left(\mathrm{N}^{-1}\right)_{4}$, this would lead to two types of anti-CD, one being $\left[\left(\mathrm{Li}^{-3}\right)\left(\mathrm{N}^{-1}\right)_{4 / 8}\right]^{3.5-}\left\{\left[\left(\mathrm{Li}^{+1}\right)\left(\mathrm{N}^{-1}\right)_{4 / 8}\right]^{+0.5}\right\}_{6 / 2}$, with a total charge of -2 , i.e. $\left[(\Psi-\mathrm{C})(\Psi-\mathrm{O})_{4 / 8}\right](\Psi-\mathrm{He})(\Psi-\mathrm{O})_{4 / 8}$, and the other 
Table 5

CD representations for cases 5 and 6 .

\begin{tabular}{|c|c|c|}
\hline $\begin{array}{l}\text { Core tetrahedron } \\
\text { Case } 5\end{array}$ & $\begin{array}{l}\text { Peripheral tetrahedron } \\
\text { Zintl-Klemm distribution }\end{array}$ & $\begin{array}{l}\text { Overall CD formula } \\
\text { n }\left(\mathrm{Li}^{+1}\right)_{3}\left(\mathrm{Li}^{-3}\right)_{0.333}\left(\mathrm{Ge}^{0}\right)_{0.667}\left(\mathrm{~N}^{-1}\right)_{2}\end{array}$ \\
\hline \multicolumn{2}{|c|}{$\left[\left(\mathrm{Li}^{-3}\right)_{0.333}\left(\mathrm{Ge}^{0}\right)_{0.667}\left(\mathrm{~N}^{-1}\right)_{4 / 8}\right]^{-1.5}\left[\mathrm{Li}^{+1}\left(\mathrm{~N}^{-1}\right)_{4 / 8}\right]^{+0.5}$} & {$\left[\left(\mathrm{Li}^{-3}\right)_{0.333}\left(\mathrm{Ge}^{0}\right)_{0.667}\left(\mathrm{~N}^{-1}\right)_{4 / 8}\right]^{-1.5}\left\{\left[\mathrm{Li}^{+1}\left(\mathrm{~N}^{-1}\right)_{4 / 8}\right]^{+0.5}\right\}_{6 / 2}$} \\
\hline $\begin{array}{l}\text { Core tetrahedron } \\
\text { Case } 6\end{array}$ & $\begin{array}{l}\text { Peripheral tetrahedron } \\
\text { Zintl-Klemm distribution }\end{array}$ & $\begin{array}{l}\text { Overall } \mathrm{CD} \text { formula } \\
\left(\mathrm{Li}^{+1}\right)_{6}\left[\left(\mathrm{Li}^{-3}\right)\left(M^{+1}\right)\right]\left(\mathrm{N}^{-1}\right)_{4}\end{array}$ \\
\hline $\begin{array}{l}\text { (1) }\left[\mathrm{Li}^{-3}\left(\mathrm{~N}^{-1}\right)_{4 / 8}\right]^{-3.5} \\
\text { (2) }\left[M^{+1}\left(\mathrm{~N}^{-1}\right)_{4 / 8}\right]^{+0.5}\end{array}$ & $\begin{array}{l}{\left[\mathrm{Li}^{+1}\left(\mathrm{~N}^{-1}\right)_{4 / 8}\right]^{+0.5}} \\
{\left[\left(\mathrm{Li}^{+1}\right)\left(\mathrm{N}^{-1}\right)_{4 / 8}\right]^{+0.5}}\end{array}$ & $\begin{array}{l}{\left[\mathrm{Li}^{-3}\left(\mathrm{~N}^{-1}\right)_{4 / 8}\right]^{-3.5}\left\{\left[\mathrm{Li}^{+1}\left(\mathrm{~N}^{-1}\right)_{4 / 8}\right]^{+0.5}\right\}_{6 / 2}(\text { net charge }-2)} \\
{\left[M^{+1}\left(\mathrm{~N}^{-1}\right)_{4 / 8}\right]^{+0.5}\left\{\left[\left(\mathrm{Li}^{+1}\right)\left(\mathrm{N}^{-1}\right)_{4 / 8}\right]^{+0.5}\right\}_{6 / 2}(\text { net charge }+2)}\end{array}$ \\
\hline
\end{tabular}

$\mathrm{Li}_{3} \mathrm{AlN}_{2}$ and its isotypes. Thus, a novel conclusion of this study is that all these structure types are satisfied at the same time, the Zintl-Klemm concept being the universal key. In other words, a given compound might result from multiple resonance structures, which implies a partial delocalization of electrons. When these are distributed over all the atoms, the electron-count requirements for each structure

$\left[M^{+1}\left(\mathrm{~N}^{-1}\right)_{4 / 8}\right]^{+0.5}\left\{\left[\left(\mathrm{Li}^{+1}\right)\left(\mathrm{N}^{-1}\right)_{4 / 8}\right]^{0.5+}\right\}_{6 / 2}$, with a total charge of +2.0 , i.e. $\left(\Psi-M^{\mathrm{IV}}\right)(\Psi-\mathrm{O})_{4 / 8}(\Psi-\mathrm{He})(\Psi-\mathrm{O})_{4 / 8}$. Thus, there is overall charge balance. This result is consistent with our earlier comment that the $\mathrm{Li}$ and $M^{\mathrm{V}}$ atoms constituting the CD cores are highly ordered, thereby ensuring that the positive and negatively charged anti-CDs are appropriately disposed with respect to their opposed anionic and cationic charges. See Table 5.

\section{Concluding remarks}

\subsection{Need for EZKC approach}

In this paper we have explored a new application of the Zintl-Klemm concept. It is well known that the classical ZintlKlemm concept (ZKC) was enunciated to account for the socalled Zintl phases in which electron transfer, from very electropositive cations to atoms of the $p$-block elements, leads to the formation of Zintl polyanions. The structure of the compound $\mathrm{NaSi}$, based on tetrahedral $\mathrm{Si}_{4}$ groups, illustrates very clearly how the $\mathrm{Si}$ atom is converted into $\mathrm{Si}^{-1}(\Psi-\mathrm{P})$ to form $(\Psi-\mathrm{P})_{4}$ molecules. Recently, Santamaría-Pérez \& Vegas (2003) and Vegas \& García-Baonza (2007) have shown that the Zintl-Klemm concept can be extended to the cation arrays of inorganic compounds. This extension of the ZKC (EZKC) necessitates charge transfer between cations, even if they are of the same atomic species. This unusual extension then ensures that this wider application of the general principle continues to be valid. The principle states that, in many compounds, the electron configurations of pairs of atoms can be rearranged to generate the characteristic structures of the Group 14 elements (Vegas \& García-Baonza, 2007).

The novelty of the present contribution is that in the case of the anti-bixbyite-type compounds derived from lithium nitride, the nitrogen can also play a central role in the interpretation and rationalization of these structures. Thus, traditional anions and cations together can be involved in the charge-transfer process in order to produce a variety of possible structures. With the compounds discussed here it is clear that the application of this extended principle can now explain why several structure types - fluorite, the hypothetical blende $\mathrm{AlBN}_{2}$ (i.e. the real blendes $\mathrm{AlN}$ and $\mathrm{BN}$ ), the real anti-bixbyite $\mathrm{Mg}_{3} \mathrm{~N}_{2}$ (von Stackelberg \& Paulus, 1933) and the real $\gamma$-Si (Kasper \& Richards, 1964) - are all identifiable in are fulfilled. This would be a new convergence point between solid state and molecular chemistry.

In the case of the quaternary compounds $\mathrm{Li}_{3}\left(\mathrm{Ge}_{0.67} \mathrm{Li}_{0.33}\right) \mathrm{N}_{2}$ and $\mathrm{Li}_{3}\left(\mathrm{Ti}_{0.67} \mathrm{Li}_{0.33}\right) \mathrm{N}_{2}$ (Juza et al., 1953), we have provided arguments to demonstrate that both the relative amounts and the exact positioning of the $\mathrm{Ge}(\mathrm{Ti})$ and $\mathrm{Li}$ atoms inside the brackets are not just coincidental.

The correlation of $\mathrm{Li}_{3} \mathrm{AlN}_{2}$ with the tetrahedral blende structures necessitates an unusual and unsymmetrical charge transfer, $\left[\mathrm{Li}^{0}\right]_{3} \rightarrow\left[\left(\mathrm{Li}^{+1}\right)_{2} \mathrm{Li}^{-2}\right]$, with two $\mathrm{Li}$ atoms donating one electron each to the third $\mathrm{Li}$ atom to give $\left(\mathrm{Li}^{+1}\right)_{2}\left[\mathrm{Li}^{-2} \mathrm{AlN}{ }_{2}\right] . \mathrm{Li}^{+1}$ is $(\Psi-\mathrm{He}) ; \mathrm{Li}^{-2}$ is $(\Psi-\mathrm{B})$, so that the anion becomes $\left(\Psi-\mathrm{BAIN}_{2}\right)$, providing the rationale for the presence of the blende-type anion in the pseudo compound, $(\Psi-\mathrm{He})\left(\Psi-\mathrm{BAlN}_{2}\right)$ represented in Fig. 6 . This could be viewed as a controversial proposal in the case of an electropositive element such as lithium: however, such unsymmetrical charge transfers are not particularly uncommon (Vegas \& GarcíaBaonza, 2007). For example, both $\mathrm{Ca}_{3} \mathrm{~N}_{2}$ and $\mathrm{Mg}_{3} \mathrm{~N}_{2}$ (von Stackelberg \& Paulus, 1933) possess anti-bixbyite structures, and, in line with the arguments developed above, the identification of a blende structure in $\mathrm{Mg}_{3} \mathrm{~N}_{2}$, for example, can be explained by assuming that one $\mathrm{Mg}$ atom transfers its two electrons to the other two $\mathrm{Mg}$ atoms so that $\mathrm{Mg}_{3}$ in $\mathrm{Mg}_{3} \mathrm{~N}_{2}$ becomes $\mathrm{Mg}^{+2}\left(\mathrm{Mg}^{-1}\right)_{2} . \mathrm{Mg}^{+2}$ is $(\Psi-\mathrm{Ne}), \mathrm{Mg}^{-1}$ is $(\Psi-\mathrm{Al})$, leading to the overall composition $(\Psi-\mathrm{Ne})(\Psi-\mathrm{Al})_{2} \mathrm{~N}_{2}$. The same description can be applied to $\mathrm{Ca}_{3} \mathrm{~N}_{2}$, although the similar ternary, mixed-cation compounds, such as $\mathrm{CaMg}_{2} \mathrm{~N}_{2}$ (SchulzCoulon \& Schnick, 1995) and $\mathrm{BaMg}_{2} \mathrm{P}_{2}$ (Klüfers \& Mewis, 1984), no longer conform to this intra-cation transfer. Thinking in classical terms of structures dominated by ionic charge and size effects, and conventional coordination polyhedra, it might be expected that the three $M$ cations $\left[\mathrm{CaMg}_{2}\right.$, $\left.\mathrm{BaMg}_{2}\right]$ would either randomly occupy the $48 e$ site of $I a \overline{3}$ or be ordered into a superstructure. However, the structure is in fact no longer anti-bixbyite, but one related to that of the Zintl phase $\mathrm{Ca}\left[\mathrm{Al}_{2} \mathrm{Si}_{2}\right]$ (Gladyshevskii et al., 1967), which is represented in Fig. 9.

The solution found by nature is quite elegant: because both $\mathrm{Ca}$ and $\mathrm{Ba}$ are more electropositive than $\mathrm{Mg}$, they donate their two valence electrons to the two $\mathrm{Mg}$ atoms, converting each into ( $\Psi$-Al), which, together with the $\mathrm{N}(\mathrm{P})$ atoms, form a fourconnected $\left(\Psi\right.$-AlN) ( $\Psi$-AlP) network typical of the $\left[\mathrm{Al}_{2} \mathrm{Si}_{2}\right]^{2-}$ Zintl polyanion, and hence of the Group 14 elements. The 
same solution was found for the compound $\mathrm{ZrNCl}$ (Vegas \& Santamaría-Pérez, 2003) in which the $[\mathrm{ZrN}]$ array transfers one electron to the $\mathrm{Cl}$ atom, giving rise to the polycation $[\mathrm{ZrN}]^{+1}$, isoelectronic with $\Psi$-YN. This is a good example of how the electron transfer acts (in this case, in the opposite direction), to produce 'Zintl polycations'.

\subsection{Experimental justification}

It is important to recall that such unexpected electron transfers are supported by NMR experiments that indicate the co-existence of entities such as $\mathrm{K}^{+}$and $\mathrm{K}^{-}$(e.g. potassides), even in the solid state (Tinkham \& Dye, 1985; Nakayama et al., 1994; Terskikh et al., 2001), so it is quite conceivable that these ions might coexist in other compounds, regardless of the fact that such entities could not be identified in conventional diffraction experiments (Seiler \& Dunitz, 1986).

In our opinion, the most remarkable finding of Niewa et al. (2003) was the coincidence of the $\gamma-\mathrm{Si}(\mathrm{Ge})$ structure with the Sc sub-array, and the consequent existence of the tetrahedral $\mathrm{ScN}_{2}$ skeleton, with covalent $\mathrm{Sc}-\mathrm{N}$ bonds. Theoretical

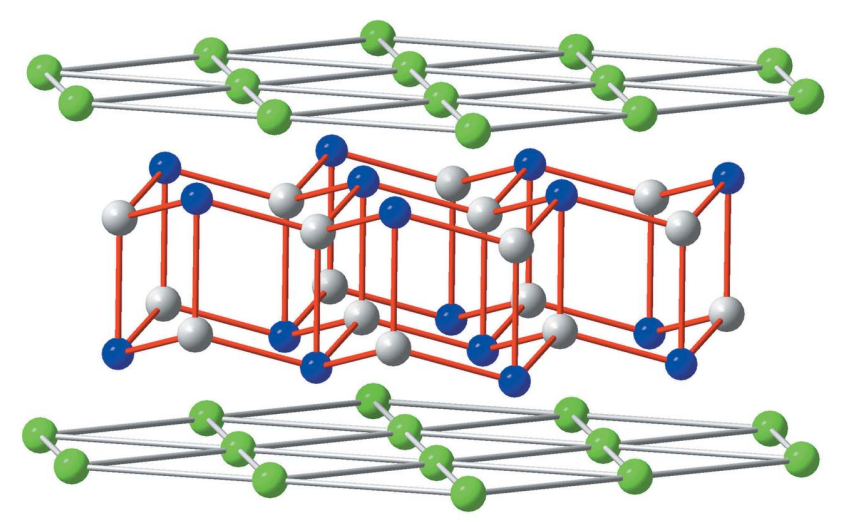

(a)

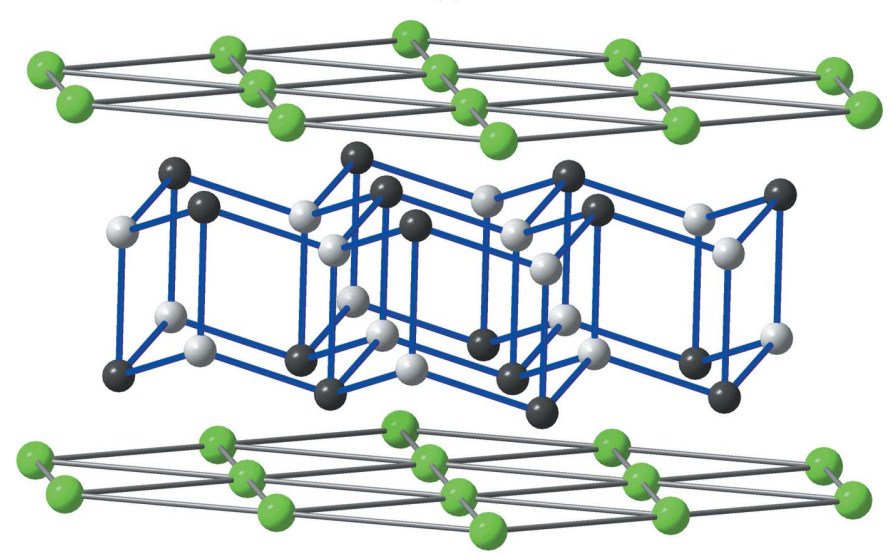

Figure 9

(b)

(a) The structure of $\mathrm{CaMg}_{2} \mathrm{~N}_{2}$. The hexagonal close packed (h.c.p.) layers of the $\mathrm{Ca}$ atoms (green spheres) are perpendicular to c. Both $\mathrm{Mg}$ and $\mathrm{N}$ atoms form bilayers in which all atoms are four-connected. The $\mathrm{Mg}$ atoms (grey spheres) are at the center of the regular tetrahedra. The $\mathrm{N}$ atoms (blue spheres) connect to four $\mathrm{Mg}$ atoms forming an umbrella-like, inverted tetrahedron. (b) The equivalent structure of $\mathrm{CaAl}_{2} \mathrm{Si}_{2}$. Grey and black spheres represent $\mathrm{Al}$ and $\mathrm{Si}$ atoms, respectively. calculations, based on the electron localization function (ELF) and periodic nodal surfaces (PNS), indicated that $\mathrm{Li}_{3} \mathrm{ScN}_{2}$ is formed by $\mathrm{Li}^{1+}$ cations inserted in a three-dimensional skeleton of $\left[\mathrm{ScN}_{2}\right]^{3-}$. The authors also mention the isostructural nitrides $\mathrm{Li}_{3} \mathrm{AlN}_{2}$ and $\mathrm{Li}_{3} \mathrm{GaN}_{2}$. It is noteworthy that this insight is only one of the many we have discovered in these stuffed bixbyites. From this point of view, the fact that the compound forms this type of structure remains unexplained. The coexistence of $\mathrm{Li}^{1+}$ cations and the tetrahedral polyanion $\left[\mathrm{ScN}_{2}\right]^{3-}$ could have been achieved with any of the many silica-like skeletons.

We have already mentioned that the isostructural compound $\mathrm{Li}_{3}\left(\mathrm{Ge}_{0.66} \mathrm{Li}_{0.33}\right) \mathrm{N}_{2}$ (Juza et al., 1953) is the key to understanding this family of compounds. However, this compound was overlooked by the authors (Niewa et al., 2003). As explained above, this compound provokes two crucial questions:

(i) Is it possible to explain a $\gamma$-Ge-type substructure for the $\left(\mathrm{Ge}_{0.66} \mathrm{Li}_{0.33}\right)$ set on the basis of the arguments given by Niewa et al. (2003)?

(ii) Why are the Ge atoms at the $16 c$ positions and not distributed at random over the other possible Li positions as in $\left(\mathrm{Li}_{2.33} \mathrm{Ge}_{0.66}\right) \mathrm{LiN}_{2}$ ?

In fact, in this latter case the anti-fluorite-type structure remains and the coordination number for all the atoms is the same. Our investigation began because we expected that a $\mathrm{Ge}(\mathrm{Si})$ atom must be at this $16 c$ position, reproducing the structure of elemental $\mathrm{Ge}$, and indeed the $\mathrm{Ge}$ atoms are there.

\subsection{New perspectives}

Inorganic solids should actually be regarded from a holistic perspective. One of the few models that can provide this holistic view is the Zintl-Klemm concept (ZKC) and its extension the EZKC. Until recently, this long-standing and illuminating concept has only been applied to the so-called Zintl phases. However, we have shown that this approach also applies successfully to the cation arrays in aluminates and silicates (Santamaría-Pérez \& Vegas, 2003; Santamaría-Pérez et al., 2005), putting this multitude (thousands of compounds), for the first time, on a common and rational basis. In a more recent article, it has been shown that the ZKC can go even further (Vegas \& García-Baonza, 2007) and provide a rational explanation of the many and varied structural types. Within this emerging pattern is where the novelty of this article resides. Here we provide a chemical reason for the experimental observation that the $\mathrm{Sc}$ sub-array in $\mathrm{Li}_{3} \mathrm{ScN}_{2}$ resembles the tetrahedral structure of $\gamma$-Si(Ge). There is a huge conceptual difference between simply pointing out this topological similarity, and describing the structure by using the ZKC. The latter enables us to explore the structures of all the likely contributing resonance compounds discussed above. For example, we are able to give a rational explanation as to why the $\mathrm{Sc}$ atoms are tetrahedrally coordinated in $\mathrm{Li}_{3} \mathrm{ScN}_{2}$, whereas they are octahedrally coordinated in the so-called interstitial nitride $\mathrm{ScN}$ ? ZKC analysis leads us to $\left[\mathrm{Sc}^{+2} \mathrm{~N}^{-2}\right]$, i.e. 
the pseudo-compound ( $\Psi$-KF) with the $\mathrm{NaCl}$ cubic closepacked structure.

In $\mathrm{Li}_{3} \mathrm{ScN}_{2}$, theoretical calculations, especially the periodic nodal surfaces, have led to the interpretation of the structure as composed of $\mathrm{Li}^{+}$cations and $\left(\mathrm{ScN}_{2}\right)^{3-}$ polyanions. However, the question is how to account for the co-existence of other complementary arrangements which involve other structure types. The structures are there and must be explained! We encourage theoreticians to elaborate new models which can help us to understand all these features.

Our conclusion is that an important procedure for gaining insight into crystal structures is not to restrict the contemplation to anions and cations in their conventional oxidation states, but also to contemplate how selected pairs of atoms might accommodate their valence electrons to produce pseudo-structures characteristic of the elements of Group 14. If this is the driving force, the conventional oxidation states assigned to cations and anions lose some of their usefulness in accounting for crystal structures.

We are gratefully indebted to Dr Javier García-García and Dr David Santamaría-Pérez for reading the manuscript and for their valuable suggestions. One of us (AV) acknowledges financial support of both the D.G.I. (Spain) under project MAT2004-05867-C03-02 and the Fundación Domingo Martínez (Valladolid, Spain).

\section{References}

Andersson, S. \& Lundström, T. (1968). Acta Chem. Scand. 22, $3103-$ 3110.

Bevan, D. J. M. \& Martin, R. L. (2008). J. Solid State Chem. 181, 2250 2259.

Eremets, M. I., Gavriliuk, A. G., Trojan, I. A., Dzivenko, D. A. \& Boehler, R. (2004). Nat. Mater. 3, 558-563.

Gladyshevskii, E. I., Krypyakevych, P. I. \& Bodak, O. I. (1967). Ukr. Phys. J. 12, 447-452.

Haines, J., Chateau, C., Leger, J. M., Bogicevic, C., Hull, S., Klug, D. D. \& Tse, J. S. (2003). Phys. Rev. Lett. 91, 015503.

Juza, R. \& Hund, F. (1948). Z. Anorg. Allg. Chem. 257, 13-25.

Juza, R., Weber, H. H. \& Meyer-Simon, E. (1953). Z. Anorg. Allg. Chem. 273, 48-64.

Kasper, J. S. \& Richards, S. M. (1964). Acta Cryst. 17, 752-755.

Klemm, W. (1958). Proc. Chem. Soc. London, pp. 329-341.

Klüfers, P. \& Mewis, A. (1984). Z. Kristallogr. 169, 135-147.

Kniep, R. (1978). Zur Kenntnis der Orthophosphate des ternären Systems $\mathrm{Al}_{2} \mathrm{O}_{3}-\mathrm{P}_{2} \mathrm{O}_{5}-\mathrm{H}_{2} \mathrm{O}$. Habilitationschrift. Universität Düsseldorf, Germany.
Kniep, R. \& Mootz, D. (1973). Acta Cryst. B29, 2292-2294.

Kniep, R., Mootz, D. \& Vegas, A. (1977). Acta Cryst. B33, 263-265.

Leib, W. \& Müller-Buschbaum, H. (1986). Rev. Chim. Miner. 23, 760765.

Martin, R. L. (1974). J. Chem. Soc. Dalton Trans. pp. 1335-1350.

Martínez-Cruz, L. A., Ramos-Gallardo, A. \& Vegas, A. (1994). J. Solid State Chem. 110, 397-398.

Nakayama, H., Klug, D. D., Ratcliffe, C. I. \& Ripmeester, J. A. (1994). J. Am. Chem. Soc. 116, 9777-9778.

Niewa, R. \& Kniep, R. (2001). Z. Kristallogr. New Cryst. Struct. 216, 5-6.

Niewa, R., Wagner, F. R., Schnelle, W., Hochrein, O. \& Kniep, R. (2001). Inorg. Chem. 40, 5215-5222.

Niewa, R., Zherebtsov, D. \& Leoni, S. (2003). Chem. Eur. J. 9, 42554259.

Owen, E. A. \& Preston, G. D. (1924). Proc. Phys. Soc. London, 36, 341-348.

Pringle, G. E. (1972). Acta Cryst. B28, 2326-2328.

Ramos-Gallardo, A. \& Vegas, A. (1995). J. Solid State Chem. 119, 131-133.

Santamaría-Pérez, D. (2006). Thesis. Universidad Carlos III. Leganés-Madrid, Spain.

Santamaría-Pérez, D. \& Vegas, A. (2003). Acta Cryst. B59, 305-323.

Santamaría-Pérez, D., Vegas, A. \& Liebau, F. (2005). Structure and Bonding, Vol. 118, pp. 121-177. Berlin: Springer Verlag.

Schulz-Coulon, V. \& Schnick, W. (1995). Z. Naturforsch. B, 50, 619622.

Seiler, P. \& Dunitz, J. D. (1986). Helv. Chim. Acta, 69, 1107-1112.

Smith, D. K., Cline, C. F. \& Austerman, S. B. (1965). Acta Cryst. 18, 393-397.

Stackelberg, M. von \& Paulus, R. (1933). Z. Phys. Chem. 22, 305-322.

Takeuchi, Y., Haga, N. \& Ito, J. (1973). Z. Kristallogr. 137, 380-398.

Terskikh, V. V., Moudrakovski, I. L., Ratcliffe, C. I. \& Ripmeester, J. A. (2001). J. Am. Chem. Soc. 123, 2891-2892.

Tinkham, M. L. \& Dye, J. L. (1985). J. Am. Chem. Soc. 107, 61296130.

Vegas, A. (2000). Crystallogr. Rev. 7, 189-286.

Vegas, A. \& García-Baonza, V. (2007). Acta Cryst. B63, 339-345.

Vegas, A., Grzechnik, A., Syassen, K., Loa, I., Hanfland, M. \& Jansen, M. (2001). Acta Cryst. B57, 151-156.

Vegas, A. \& Jansen, M. (2002). Acta Cryst. B58, 38-51.

Vegas, A. \& Santamaría-Pérez, D. (2003). Z. Kristallogr. 218, 466469.

Vennos, D. A. \& DiSalvo, F. J. (1992). Acta Cryst. C48, 610-612.

Wachsmann, C. \& Jakobs, H. (1992). J Alloys Compd. 190, 113116.

Wakatsuki, M., Ichinose, K. \& Aoki, T. (1972). Mater. Res. Bull. 7, 999-1004.

Wells, A. F. (1975). Structural Inorganic Chemistry, 4th ed. Oxford: Clarendon Press.

Wentorf, R. H. Jr \& Kasper, J. S. (1963). Science, 139, 338-339.

Zachariasen, W. H. (1928). Skr. Nor. Vidensk. p. 6.

Zintl, E. (1939). Angew. Chem. 52, 1-6. 